CENTRE for ECONOMIC

$P$ E R F O R M A N C E

CEP Discussion Paper No 690

May 2005

\title{
Labor and the Market Value of the Firm
}

Monika Merz and Eran Yashiv

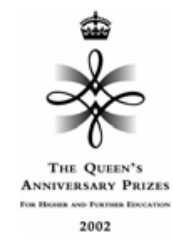




\begin{abstract}
What role does labor play in a firm's market value? We explore this question using a production-based asset pricing model with frictions in the adjustment of both capital and labor. We posit that hiring of labor is akin to investment in capital and that the two interact, with the interaction being a crucial determinant of the time series behavior of market value. We use aggregate U.S. corporate sector data to estimate firms' optimal hiring and investment decisions and the consequences for firms' value. The model generates a good fit of the data. We decompose the estimated market value, thereby quantifying the link between firms' value and gross hiring flows, employment, gross investment flows, and physical capital. We find that a conventional specification -- quadratic adjustment costs for capital and no hiring costs -- performs poorly. Hiring and investment flows, unlike employment and capital stocks, are volatile and both are essential to account for market value volatility. A key result is that firms' value embodies the value of hiring and investment over and above the capital stock.
\end{abstract}

Keywords: production-based asset pricing, labor market frictions, gross flows, Q-model, GMM

JEL Classifications: E22, E23, E24,G12

Data: U.S NIPA and BLS data

This paper was produced as part of the Centre's Technology and Growth Programme. The Centre for Economic Performance is financed by the Economic and Social Research Council.

\title{
Acknowledgements
}

We thank two anonymous referees and seminar participants at Princeton, NYU, Maryland, Minneapolis Fed, NY Fed, the 2003 AEA meetings, the 2003 SED meetings in Paris, the 2002 NBER Summer Institute, Rice, University College London, the London School of Economics, London Business School, Imperial College, Tel Aviv (Eitan Berglas School of Economics and Recanati School of Business), the CentER in Tilburg, ECARE, the Norwegian School of Business, the University of Oslo, the June 2002 CEPR conference on dynamic aspects of unemployment at CREST, Paris, the 2002 annual meeting of the EEA in Venice, and the December 2001 conference on finance and labor market frictions at the University of Bonn for comments on previous versions of the paper. We are grateful to Andy Abel, Michael Burda, Craig Burnside, Zvi Eckstein, Peter Hartley, Zvi Hercowitz, Urban Jermann, Martin Lettau, Masao Ogaki, Harald Uhlig and Itzhak Zilcha for useful suggestions, to Hoyt Bleakley, Ann Ferris, Jeff Fuhrer and Elizabeth Walat for their worker flows series, to Bob Hall for market value data, to Flint Brayton for tax and depreciation series, and to Michael Ornstein and, in particular, Darina Vaissman for excellent research assistance. Any errors are our own.

Monika Merz is a Professor of Economics at the University of Bonn. Email: mmerz@uni-bonn.de

Web page: http://www.iiw.uni-bonn.de/merz/ Eran Yashiv is a Visiting Professor to the Department of

Economics, London School of Economics from Tel Aviv University. Email: yashiv@post.tau.ac.il

Web page: $\underline{\text { http://www.tau.ac.il/ ryashiv }}$

Published by

Centre for Economic Performance

London School of Economics and Political Science

Houghton Street

London WC2A 2AE

All rights reserved. No part of this publication may be reproduced, stored in a retrieval system or transmitted in any form or by any means without the prior permission in writing of the publisher nor be issued to the public or circulated in any form other than that in which it is published.

Requests for permission to reproduce any article or part of the Working Paper should be sent to the editor at the above address.

(C) M. Merz and E. Yashiv, submitted 2005

ISBN 0753018705 


\section{Labor and the Market Value of the Firm}

\section{Introduction}

What role does labor play in the market value of firms? According to the frictionless neoclassical model - a benchmark for our exploration - labor is not a part of this value, because it is costlessly adjusted and hence receives its share in output. In this frictionless environment the firm's market value equals its stock of physical capital. When combining this setup with adjustment costs of physical capital as in Tobin (1969) or Tobin and Brainard (1977), the well-known Tobin's Q-model results. Adjustment costs of capital involve implementation costs, the learning of new technologies, or the fact that production is temporarily interrupted. The standard Q-model still assigns no explicit role for labor, as determination of the firm's value only requires correction for the value of the capital adjustment technology. Labor explicitly enters the picture whenever there are frictions in the labor market [see the discussion in Danthine and Donaldson (2002a)]. With frictional labor markets, labor is a quasi-fixed factor from which a firm extracts rents. These rents compensate it for the costs associated with adjusting the work force. The firm's value needs to take these rents into account. 
In this paper we build on the production-based model for firms' market value proposed by Cochrane $(1991,1996)$ and insert frictional labor markets and capital adjustment costs as crucial ingredients. We represent labor market frictions by trade frictions between searching firms and workers, and by advertising, screening, and training costs [Mortensen and Pissarides (1999) survey the relevant search and matching literature]. We let the adjustment costs for labor interact with those for capital, with all adjustment costs relating to gross rather than to net changes. This specification allows us to simultaneously study the dynamic behavior of variables which hitherto have been explored separately. In particular, we qualitatively illustrate how firms' market value is linked to the flows of gross hiring and gross investment and to the stocks of employment and physical capital. This link results from the following economic mechanism. Firms decide on the number of vacancies to post in order to hire workers and on the size of the investment in physical capital to undertake in their effort to maximize their market value. Doing so they face labor market frictions interacting with adjustment costs for capital. Optimal hiring and investing determines firms' profits - including rents from employment - and consequently their value, as well as the time path of employment and capital.

We quantify this link by structurally estimating the model using aggregate time-series data for the U.S. corporate sector. Our data set has a number of distinctive features. It makes use of gross rather than net hiring flow series, the former exhibiting considerable volatility; data on output, gross investment and the capital stock, as well as market value data, pertain to the non-financial corporate business sector rather than to broader, but inappropriate measures of the U.S. economy; alternative, time-varying discount rates are examined; and key elements of the corporate tax structure are explicitly taken into account. We use alternative convex adjustment costs specifications and a nonlinear, structural estimation procedure in order to allow for a more general framework than the traditional quadratic cost formulation that dominates most of the related literature.

The main goal of our empirical work is to explain firms' joint hiring and investment behavior and its implications for market values. Towards this end we estimate the firms' adjustment costs function. Our results suggest that this exploration is worthwhile. With a reasonable magnitude for 
adjustment costs, we can characterize optimal hiring and investment. The implied value of hiring and that of investment account fairly well for the predicted component of firms' value, over and above the size of the physical capital stock. We decompose firms' value in terms of both mean and volatility. We find that factor adjustment costs play a role in explaining the mean of market values, and that volatility cannot be explained without both capital and labor adjustment costs.

Our paper makes several contributions. First, the model qualitatively derives the link between firms' market value and gross hires, employment, gross investment and physical capital, thereby showing that, in addition to capital, labor matters. The empirical results lend quantitative support to this link. The reason for the relative success here - comparing to previous formulations which have failed - lies in the examination of investment and hiring costs jointly and in terms of gross flows. Note that much of the literature either focused on one and ignored the other, or dealt with net changes rather than with gross flows. Second, the paper puts the Q-model on a much more solid empirical footing, thereby explaining the weakness of previous results and demonstrates the role of labor market frictions for the behavior of investment and firms' market value. Finally, the paper generates a structural specification of a production-based asset pricing model, linking financial variables to macroeconomic ones.

The paper proceeds as follows. Section 2 presents the model. Section 3 discusses the data and the empirical methodology. Section 4 presents the results. Section 5 derives the implications with respect to the adjustment costs function, to the performance of the estimated optimality equations, and to the joint behavior of hiring and investment. Section 6 discusses the implications for market values. Section 7 summarizes the key results and concludes. Technical derivations, data definitions, and robustness checks are elaborated in appendices. 


\section{The Model}

We delineate the partial equilibrium model which serves as the basis for estimation. ${ }^{2}$

\subsection{The Economic Environment}

The economy is populated by identical workers and identical firms. All agents live forever and have rational expectations. Workers and firms interact in the markets for goods, labor, capital, and financial assets. This setup deviates from the standard neoclassical framework. That is, it takes time and resources for firms to adjust their capital stock, or to hire new workers. All variables are expressed in terms of the output price level.

\subsection{Hiring and Investment}

Firms make investment and hiring decisions. They own the physical capital stock $k$ and decide each period how much to invest in capital, $i$. In order to attract new workers, a firm needs to post a job-vacancy $v$. For each vacancy posted, the firm takes as given the rate $q$ at which this vacancy is filled with a non-employed worker. Hence, in every period, a firm's gross hires are given by $q v .^{3}$ Once a new worker is hired, the firm pays her a per-period gross compensation rate $w$. Firms use physical capital and labor as inputs in order to produce output goods $y$ according to a constant-returns-to-scale production function $f$ with productivity shock $z$ :

$$
y_{t}=f\left(z_{t}, n_{t}, k_{t}\right),
$$

Gross hiring and gross investment are costly activities. Hiring costs include advertising, screening, and training. In addition to the purchase costs, investment involves capital installation costs, learning the use of new equipment, etc. Adjusting labor or capital involves disruptions to

\footnotetext{
${ }^{2}$ The parts concerned with the labor market follow the prototypical search and matching model within a stochastic framework. See Pissarides (2000) and Yashiv (2000).

${ }^{3}$ In the standard matching model, those gross hires are labeled new job-matches, and the transition rate $q$ for a vacancy equals the ratio of job-matches to vacancies posted.
} 
production, and potentially also the implementation of new organizational structure within the firm and new production practices. All of these costs reduce the firm's profits. We represent these costs by an adjustment costs function $g\left[i_{t}, k_{t}, q_{t} v_{t}, n_{t}\right]$ which is convex in the firm's decision variables and exhibits constant returns-to-scale. We allow hiring costs and capital adjustment costs to interact. We specify the functional form of $g$ in the empirical work below.

In every period $t$, the capital stock depreciates at the rate $\delta_{t}$ and is augmented by new investment $i_{t}$. The capital stock's law of motion equals:

$$
k_{t+1}=\left(1-\delta_{t}\right) k_{t}+i_{t}, \quad 0 \leq \delta_{t} \leq 1
$$

Similarly, the number of a firm's employees decreases at the rate $\psi_{t}$. It is augmented by new hires $q_{t} v_{t}:$

$$
n_{t+1}=\left(1-\psi_{t}\right) n_{t}+q_{t} v_{t}, \quad 0 \leq \psi_{t} \leq 1
$$

Firms' profits before tax, $\pi$, equal the difference between revenues net of adjustment costs and total labor compensation, wn:

$$
\pi_{t}=\left[f\left(z_{t}, n_{t}, k_{t}\right)-g\left(i_{t}, k_{t}, q_{t} v_{t}, n_{t}\right)\right]-w_{t} n_{t} .
$$

Every period, firms make after-tax cash flow payments $c f$ to the stock owners and bond holders of the firm. These cash flow payments equal profits after tax minus purchases of investment goods plus investment tax credits and depreciation allowances for new investment goods:

$$
c f_{t}=\left(1-\tau_{t}\right) \pi_{t}-\left(1-\chi_{t}-\tau_{t} D_{t}\right) \widetilde{p}_{t}^{I} i_{t}
$$

where $\tau_{t}$ is the corporate income tax rate, $\chi_{t}$ the investment tax credit, $D_{t}$ the present discounted value of capital depreciation allowances, $\tilde{p}_{t}^{I}$ the real pre-tax price of investment goods.

The representative firm's ex dividend market value in period $t, s_{t}$, is defined as follows:

$$
s_{t}=E_{t}\left[\beta_{t+1}\left(s_{t+1}+c f_{t+1}\right)\right]
$$


Solving equation (2.6) forward, we can alternatively define the firm's market value in period $t$ as the present discounted value of future cash flows:

$$
s_{t}=E_{t}\left\{\sum_{j=1}^{\infty}\left(\prod_{i=1}^{j} \beta_{t+i}\right) c f_{t+j}\right\},
$$

where $E_{t}$ denotes the expectational operator conditional on information available in period $t$. The discount factor between periods $t+j-1$ and $t+j$ for $j \in\{1,2, \ldots\}$ is given by:

$$
\beta_{t+j}=\frac{1}{1+r_{t+j-1, t+j}}
$$

where $r_{t+j-1, t+j}$ denotes the time-varying discount rate between periods $t+j-1$ and $t+j$. Appendix $\mathrm{B}$ contains a detailed description of how alternative values of the discount rate $r$ are computed in the empirical work.

The representative firm chooses sequences of $i_{t}$ and $v_{t}$ in order to maximize its cum dividend market value $c f_{t}+s_{t}$ :

$$
\max _{\left\{i_{t+j}, v_{t+j}\right\}} E_{t}\left\{\sum_{j=0}^{\infty}\left(\prod_{i=0}^{j} \beta_{t+i}\right) c f_{t+j}\right\}
$$

subject to the definition of $c f_{t+j}$ in equation (2.5) and the constraints (2.2) and (2.3). The firm takes the variables $q, w, p^{I}, \delta, \psi$, and $\beta$ as given. The Lagrange multipliers associated with these two constraints are $Q_{t+j}^{K}$ and $Q_{t+j}^{N}$, respectively. These Lagrange multipliers can be interpreted as marginal $Q$ for physical capital, and marginal $Q$ for employment, respectively.

The accompanying first-order necessary conditions for dynamic optimality are the same for any two consecutive periods $t+j$ and $t+j+1, j \in\{0,1,2, \ldots\}$. We denote by $f_{x}$ the marginal product of factor $x$, and by $g_{x}$ the marginal cost of raising variable $x$. For the sake of notational 
simplicity, we drop the subscript $j$ from the respective equations to follow:

$$
\begin{aligned}
Q_{t}^{K} & =E_{t}\left\{\beta_{t+1}\left[\left(1-\tau_{t+1}\right)\left(f_{k_{t+1}}-g_{k_{t+1}}\right)+\left(1-\delta_{t+1}\right) Q_{t+1}^{K}\right]\right\} \\
Q_{t}^{K} & =\left(1-\tau_{t}\right)\left(g_{i_{t}}+p_{t}^{I}\right) \\
Q_{t}^{N} & =E_{t}\left\{\beta_{t+1}\left[\left(1-\tau_{t+1}\right)\left(f_{n_{t+1}}-g_{n_{t+1}}-w_{t+1}\right)+\left(1-\psi_{t+1}\right) Q_{t+1}^{N}\right]\right\} \\
Q_{t}^{N} & =\left(1-\tau_{t}\right) \frac{g_{v_{t}}}{q_{t}}
\end{aligned}
$$

where we use the real after-tax price of investment goods, given by:

$$
p_{t+j}^{I}=\frac{1-\chi_{t+j}-\tau_{t+j} D_{t+j}}{1-\tau_{t+j}} \widetilde{p}_{t+j}^{I} .
$$

Dynamic optimality requires the following two transversality conditions to be fulfilled

$$
\begin{aligned}
\lim _{T \rightarrow \infty} E_{T}\left(\beta_{T} Q_{T}^{K} k_{T+1}\right) & =0 \\
\lim _{T \rightarrow \infty} E_{T}\left(\beta_{T} Q_{T}^{N} n_{T+1}\right) & =0 .
\end{aligned}
$$

We can summarize the firm's first-order necessary conditions from equations (2.9)-(2.12) by the following two expressions:

$$
\begin{aligned}
& F 1:\left(1-\tau_{t}\right)\left(g_{i_{t}}+p_{t}^{I}\right)=E_{t}\left\{\beta_{t+1}\left(1-\tau_{t+1}\right)\left[f_{k_{t+1}}-g_{k_{t+1}}+\left(1-\delta_{t+1}\right)\left(g_{i_{t+1}}+p_{t+1}^{I}\right)\right]\right\} \\
& F 2: \quad\left(1-\tau_{t}\right) \frac{g_{v_{t}}}{q_{t}}=E_{t}\left\{\beta_{t+1}\left(1-\tau_{t+1}\right)\left[f_{n_{t+1}}-g_{n_{t+1}}-w_{t+1}+\left(1-\psi_{t+1}\right) \frac{g_{v_{t+1}}}{q_{t+1}}\right]\right\} .
\end{aligned}
$$

Solving equation (2.9) forward and using the law of iterated expectations expresses $Q_{t}^{K}$ as the expected present value of future marginal products of physical capital net of marginal capital adjustment costs:

$$
Q_{t}^{K}=E_{t}\left\{\sum_{j=0}^{\infty}\left(\prod_{i=0}^{j} \beta_{t+1+i}\right)\left(\prod_{i=0}^{j}\left(1-\delta_{t+1+i}\right)\right)\left(1-\tau_{t+1+j}\right)\left(f_{k_{t+1+j}}-g_{k_{t+1+j}}\right)\right\} .
$$

It is straightforward to show that in the special case of time-invariant discount factor, depreciation rate and price of investment goods, no adjustment costs, no taxes, and a perfectly competitive market for capital, $Q_{t}^{K}$ equals the price of investment goods $p^{I}$. Similarly, solving equation (2.11) 
forward and using the law of iterated expectations expresses $Q_{t}^{N}$ as the expected present value of the future stream of surpluses arising to the firm from an additional hire of a new worker:

$$
Q_{t}^{N}=E_{t}\left\{\sum_{j=0}^{\infty}\left(\prod_{i=0}^{j} \beta_{t+1+i}\right)\left(\prod_{i=0}^{j}\left(1-\psi_{t+1+i}\right)\right)\left(1-\tau_{t+1+j}\right)\left(f_{n_{t+1+j}}-g_{n_{t+1+j}}-w_{t+1+j}\right)\right\} .
$$

In the special case of a perfectly competitive labor market and no hiring costs, $Q_{t}^{N}$ equals zero.

\subsection{Implications For Asset Values}

We use standard asset-pricing theory to derive the implications of the model for the links between the market value of the firm and the asset value of a new hire. As stated in equation (2.6), the firm's period $t$ market value is defined as the expected discounted pre-dividend market value of the following period:

$$
s_{t}=E_{t}\left[\beta_{t+1}\left(s_{t+1}+c f_{t+1}\right)\right] .
$$

The firm's market value can be decomposed into the sum of the value due to physical capital, $\vartheta_{t}^{k}$, and the value due to the stock of employment, $\vartheta_{t}^{n}$. We label the latter fraction of the firm's market value the asset value of a new hire and express $s_{t}$ as

$$
s_{t}=\vartheta_{t}^{k}+\vartheta_{t}^{n}=E_{t}\left[\beta_{t+1}\left(\vartheta_{t+1}^{k}+c f_{t+1}^{k}\right)\right]+E_{t}\left[\beta_{t+1}\left(\vartheta_{t+1}^{n}+c f_{t+1}^{n}\right)\right],
$$

Using the constant returns-to-scale properties of the production function $f$ and of the adjustment cost function, $g$, we rely on equation (2.5) when decomposing the stream of maximized cash flow payments as follows:

$$
\begin{aligned}
c f_{t} & =\left(1-\tau_{t}\right)\left(f_{k_{t}} k_{t}+f_{n_{t}} n_{t}-w_{t} n_{t}-p_{t}^{I} i_{t}-g_{k_{t}} k_{t}-g_{i_{t}} i_{t}-g_{n_{t}} n_{t}-g_{v_{t}} v_{t}\right) \\
& =\left(1-\tau_{t}\right)\left[\left(f_{k_{t}} k_{t}-p_{t}^{I} i_{t}-g_{k_{t}} k_{t}-g_{i_{t}} i_{t}\right)+\left(f_{n_{t}} n_{t}-w_{t} n_{t}-g_{n_{t}} n_{t}-g_{v_{t}} v_{t}\right)\right] \\
& \equiv c f_{t}^{k}+c f_{t}^{n} .
\end{aligned}
$$

In order to establish a link between the firm's market value and its stock of capital and employment using the first-order necessary condition (FONC) we manipulate the latter equation to obtain (see 
Appendix A for the full derivation) the central asset pricing equation relying on the afore-cited CRS properties of $f$ and $g$ :

$$
s_{t}=\vartheta_{t}^{k}+\vartheta_{t}^{n}=k_{t+1} Q_{t}^{K}+n_{t+1} Q_{t}^{N}
$$

where $Q_{t}^{K}$ and $Q_{t}^{N}$ are defined in equations (2.15) and (2.16), respectively.

Equation (2.19) summarizes an important qualitative result. With frictional labor markets, the shadow value of employment typically is non-zero. Hence in such settings, the level of employment, multiplied by the respective shadow value, enters the firm's market value. Put differently, equation (2.19) illustrates the fact that the current model generalizes the neoclassical formulation, whereby the firm's market value equals its physical capital stock, to an environment with capital adjustment costs and labor market frictions. Note that, using the expressions (2.9)-(2.12) we can alternatively express the firm's market value in period $t$ as follows:

$$
\begin{aligned}
s_{t}= & k_{t+1} E_{t}\left\{\beta_{t+1}\left(1-\tau_{t+1}\right)\left[f_{k_{t+1}}-g_{k_{t+1}}+\left(1-\delta_{t+1}\right)\left(p_{t+1}^{I}+g_{i_{t+1}}\right)\right]\right\} \\
& +n_{t+1} E_{t}\left\{\beta_{t+1}\left(1-\tau_{t+1}\right)\left(f_{n_{t+1}}-g_{n_{t+1}}-w_{t+1}+\left(1-\psi_{t+1}\right) \frac{g_{v_{t+1}}}{q_{t+1}}\right)\right\}
\end{aligned}
$$

Next we turn to explore the empirical implications of the model. One of them shall be the estimation of the asset values of investment $\left(Q^{K}\right)$ and hiring $\left(Q^{N}\right)$. Thus, while these are not priced on the market, we shall obtain estimates of the market value of investment and of hiring, which - were they to be priced on the market - would be akin to the stock price of investment and the stock price of hiring.

\section{Data and Methodology}

The adjustment cost function $g$ is the main object of structural estimation. We present the parameterization of this function as well as of the production function, and the econometric methodology. This presentation includes a discussion of data and econometric issues and the resulting alternative specifications. 


\subsection{Parameterization}

To quantify the model we need to parameterize the relevant functions. For the production function we use a standard Cobb-Douglas:

$$
f\left(z_{t}, n_{t}, k_{t}\right)=e^{z_{t}} n_{t}^{\alpha} k_{t}^{1-\alpha}, 0<\alpha<1 .
$$

For the adjustment costs function $g$, following the results of structural estimation of the aggregate search and matching model in Yashiv (2000) and some experimentation, we adopt the following generalized convex function:

$$
g(\cdot)=\left[f_{1} \frac{i_{t}}{k_{t}}+f_{2} \frac{q_{t} v_{t}}{n_{t}}+\frac{e_{1}}{\eta_{1}}\left(\frac{i_{t}}{k_{t}}\right)^{\eta_{1}}+\frac{e_{2}}{\eta_{2}}\left(\frac{q_{t} v_{t}}{n_{t}}\right)^{\eta_{2}}+\frac{e_{3}}{\eta_{3}}\left(\frac{i_{t}}{k_{t}} \frac{q_{t} v_{t}}{n_{t}}\right)^{\eta_{3}}\right] f\left(z_{z}, n_{t}, k_{t}\right) .
$$

This function is linearly homogenous in its four arguments $i, v, k$ and $n$. The function postulates that costs are proportional to output, and that they increase in investment and hiring rates. Recent work by Cooper and Willis (2003) and Cooper and Haltiwanger (2005, see in particular pp. 23-24) gives empirical support to the use of a convex adjustment costs function. They showed that while non-convexities may matter at the micro level, a convex formulation is appropriate at the aggregate, macroeconomic level. The above specification captures the idea that the disruption in the production process increases with the extent of the factor adjustment relative to the size of the firm, where a firm's size is measured by its physical capital stock, or its level of employment. The last term in square brackets expresses the interaction of capital and labor adjustment costs. The parameters $f_{1}, f_{2}$ and $e_{1}$ through $e_{3}$ express scale, and $\eta_{1}$ through $\eta_{3}$ express the elasticity of adjustment costs with respect to the different arguments. The function encompasses the widely used quadratic case for which $\eta_{1}=\eta_{2}=2$. The estimates of these parameters will allow the quantification of the derivatives $g_{i_{t}}$ and $g_{v_{t}}$ and, hence, the marginal adjustment cost of investment and hiring, respectively, that appear in the firms' FONC. 


\subsection{The Data}

Our data sample is quarterly, corporate sector data for the U.S. economy from 1976:1 to 2002:4. The beginning of the sample period is constrained by the availability of consistent gross worker flow data, and its end by the availability of consistent investment and capital data. In what follows we briefly describe the data set and emphasize its distinctive features; for full definitions and sources see Appendix B. Table 1 presents summary statistics of the series used.

\section{See Table 1 (p.xviii)}

For output $f$, capital $k$, investment $i$, and depreciation $\delta$ we use a new data set on the nonfinancial corporate business (NFCB) sector recently published by the Bureau of Economic Analysis (BEA) of the U.S. Department of Commerce ${ }^{4}$ and quarterly investment series from the Federal Reserve Board. This data set leaves out variables that are often used in the literature but that are not consistent with the above model, such as residential or government investment.

For gross hiring flows $q v$ and for the separation rate $\psi$ we use series based on adjusted Current Population Survey (CPS) data as computed by Bleakely et al. (1999), adjusted to represent the NFCB sector. Two aspects of the data merit attention: (i) We use gross flows between employment and both unemployment and out of the labor force $;^{5}$ the latter flows (out of the labor force to employment) are sizeable, and in terms of the model are not different from unemployment - employment flows. (ii) The gross worker flows are adjusted to cater for misclassification and measurement error. ${ }^{6}$ For the labor share of income $\frac{w n}{f}$ we use the compensation of employees, i.e.,

\footnotetext{
${ }^{4}$ See www.bea.doc.gov/bea/ARTICLES/NATIONAL/NIPAREL/2000/0400fxacdg.pdf The investment rate series $\frac{i_{t}}{k_{t}}$ for this sector is very similar to the private sector non-residential series with roughly the same mean, a slightly higher variance and a correlation of 0.94 ; the average output series $\frac{f}{k}$ is also very similar, with slightly lower mean and variance and a correlation of 0.92 with the private sector non-residential series.

${ }^{5}$ The difference in size between gross and net worker flows is noteable. Gross flows per quarter amount to 9 percent of employment, whereas net flows equal 0.5 percent only.

${ }^{6}$ See Bleakely et al. (1999) for a discussion of the adjustment methodology. The construction of the series used here is explained in Appendix B.
} 
the sum of wage and salary accruals and supplements to wages and salaries as a fraction of the gross product of the non-financial corporate sector. We take the latter variable from the National Income and Product Accounts (NIPA).

We measure firms' market value $s$ using the market value of all non-farm, non-financial corporate businesses. This value equals the sum of financial liabilities and equity less financial assets. The data are taken from Hall (2001) based on the Federal Reserve's Flow of Funds accounts. This series in a detrended version is highly correlated with stock market measures such as the total market value reported by the Center for Research in Security Prices (CRSP) at the University of Chicago, or the SP500 index. For the discount rate $r$ we use a weighted average of the returns to debt (using a commercial paper rate) and to equity (using CRSP returns), with changing weights reflecting actual debt and equity finance shares. We also test two alternatives for $r$, the SP500 rate of change, and the rate of non-durable consumption growth, which serves as the discount rate in many dynamic stochastic general equilibrium models featuring log utility.

\subsection{Methodology}

We structurally estimate the firms' first-order necessary conditions $(F 1)$ and $(F 2)$, and the asset pricing equation (2.20) using Hansen's (1982) generalized method of moments (GMM). The moment conditions estimated are those obtained under rational expectations. That is, the firms' expectational errors are orthogonal to any variable in their information set at the time of the investment and hiring decisions. The moment conditions are derived by replacing expected values with actual ones plus expectational errors $j$ and specifying that the errors are orthogonal to the instruments $Z$, i.e., $E\left(j_{t} \otimes Z_{t}\right)=0$. We formulate the equations in stationary terms by dividing the FONC for

capital by $\frac{f_{t}}{k_{t}}$, the FONC for labor by $\frac{f_{t}}{n_{t}}$, and the asset pricing equation throughout by the level of output, $f_{t}$. We elaborate on the estimation methodology in Appendix C.

We explore a number of alternative specifications:

1) The degree of convexity of the g function. A major issue proves to be the degree of 
convexity of the $g$ function. The literature has for the most part assumed quadratic adjustment costs. We examine more general convex functions, either by estimating the power parameters $\left(\eta_{1}, \eta_{2}, \eta_{3}\right)$ or by constraining them to take different values.

2) Instrument sets. We use alternative instrument sets in terms of variables and number of lags. The instrument sets include lags of variables that appear in the equations.

3) Variables' formulation. We check the effect of using alternative time series for some of the variables, which have multiple representations. These include $\frac{q v}{n}, \psi, \delta$ and $\beta$.

We check whether the estimated $g$ function is reasonable in that it fulfills not only the convexity requirement but also implies total and marginal adjustment costs that lie within a plausible range. We discuss what such a range might be below.

\section{Estimation Results}

The focal point of the empirical work is estimation of the parameters of the adjustment costs function $g$. These estimates allow us to generate time series for the costs of hiring and investing, and for firms' market values, thereby quantifying the links between these three series. The literature has typically used a quadratic specification for capital adjustment costs and ignored possible interactions between hiring and investment costs. ${ }^{7}$ Our results suggest that modifying this specification is essential.

Table 2 reports the results of the joint GMM estimation of the firms' first-order conditions

\footnotetext{
${ }^{7}$ Nadiri and Rosen (1969) examined both capital and labor adjustment costs, and since then a number of papers have done so. The most notable contribution in the current context is Shapiro (1986), who used structural estimation. Our paper differs along several dimensions:(i) labor adjustment costs here pertain to gross costs and therefore are a function of gross worker flows into employment; in Shapiro (and other work) they pertain to net costs and relate to changes in the employment stock, which are considerably smaller; (ii) the current paper uses the market values of firms in estimation while no such information is used in Shapiro; (iii) the latter paper uses linear-quadratic adjustment costs, a formulation found to be too restrictive here; (iv) Shapiro's uses data on manufacturing while here non-financial corporate business data are used; (v) the discount rate in Shapiro is a T-bill rate plus a risk premium, while here alternative time-varying rates are used.
} 
$(F 1)$ and $(F 2)$, and the asset pricing equation (2.20). We present the point estimates of the power parameters $\eta_{1}$ through $\eta_{3}$, the scale parameters $f_{1}, f_{2}$ and $e_{1}$ through $e_{3}$, the employment elasticity of output, $\alpha$, the standard errors of the estimates (except where constrained), and the J statistics.

Throughout, the labor elasticity parameter $\alpha$ is estimated at 0.68 or 0.69 , with low standard errors. This conforms with standard estimates and serves as a validity check on our estimation procedure.

Column (1) is the most general, with all parameters freely estimated. This means that the shape and degree of convexity of the $g$ function are left for estimation and allowed to vary across the different arguments of the function. The results point to an approximately cubic specification for investment and hiring $\left(\eta 1=2.8, \eta_{2}=3.4\right)$ and to a quadratic interaction term $(\eta 3=2)$. Except for the estimates of the parameters of the linear terms $\left(f_{1}\right.$ and $\left.f_{2}\right)$, which exhibit large standard errors, all parameters are relatively precisely estimated. The other columns impose more structure. Column (2), (3), and (4) allow one power parameter to be free, constraining the other two to the values estimated in column (1). In these three columns the standard errors of the scale parameters estimates go down, but the point estimates of all parameters remain very close to those of column (1). Columns (5), (6) and (7) impose a further restriction, by setting the coefficients of the linear terms at the levels estimated in columns (1)-(4), i.e., setting $f_{1}=2, f_{2}=-2$. This leads to some further reduction in the standard errors, but, again, the point estimates hardly change. In those last three columns, all parameters are very precisely estimated.

Hence, across all seven columns, the point estimates lie in a narrow range. The differences across columns are mainly in the precision (standard errors) of the estimates. Appendix C (see Tables C-2, C-3 and C-4) looks at further variations to check for robustness.

Table 3 attempts to gauge the value added of the different components of our specification by imposing restrictions. 
Column 1 reports the traditional equation estimated in the Q-literature, i.e., quadratic adjustment costs of capital only. This means that we impose $f_{1}=f_{2}=e_{2}=e_{3}=0$ and $\eta_{1}=2$. The results are a precisely estimated scale parameter $e_{1}$ but the production function parameter $\alpha$ is estimated at a particularly high level and the J-statistic indicates rejection. Indeed, we show below that the fit of this specification is poor. Column 2 re-introduces the linear terms and takes a cubic for the power specification of $\eta_{1}$ and $\eta_{2}$. In other words it improves on the standard quadratic by postulating a linear-cubic formulation and by taking into account hiring costs. But it does not allow for any interaction between capital adjustment costs and hiring costs, i.e., $e_{3}=0$ is imposed. This restriction yields point estimates that are different from those of Table 2, a particularly low level of $\alpha$, and the J-statistic indicates rejection. As we show below, the fit of this specification turns out to be mediocre at best. In column 3 we replicate the basic specification of Table 2 but estimate only the investment optimality equation $(F 1)$ and the asset pricing equation (2.20), i.e., we drop the hiring optimality $(F 2)$ equation. We get point estimates that are close to those of Table 2 but less precise.

We turn now to examine the implications of these estimates for the adjustment costs function and for the time series behavior of hiring, investment and asset values. Doing so we shall evaluate the model-data fit. As the results of Table 2 (and those reported in Tables C-2, C-3, and C-4 in Appendix $\mathrm{C}$ below) are very similar in terms of point estimates across specifications, we shall report one representative specification - that of column (7) in Table 2 - in what follows. Whenever relevant, we shall also look at the results of Table 3, columns 1 and 2.

\section{The Value of Hiring and Investment}

In this section we look at the implications for hiring and for investment of the results using the point estimates reported in Tables 2 and 3. We begin by looking at the implied adjustment costs function (section 5.1); we then examine the performance of the estimating optimality equations for 
hiring and investment (section 5.2); finally, we study the joint behavior of hiring and investment (section 5.3).

\subsection{Adjustment Costs and the Value of Hiring and Investment}

The results allow us to construct time series for total and marginal adjustment costs by using the point estimates of the parameters of the $g$ function. Knowing these is important, as they are also the asset values of investment $\left(Q^{K}\right)$ and hiring $\left(Q^{N}\right)$, or put differently, these are the "stock prices" of investment and hiring.

In Table 4 we report the moments for total and marginal adjustment costs using the point estimates reported in Table 2 (column 7 ) and in Table 3 (column 1). The table reports the value of each expression at the sample mean and the precision of the estimates. ${ }^{8}$

\section{SeT able 4 (p.xxiii)}

First, we shall refer only to the estimates based on the representative specification of Table 2 (column 7). The first row reports total costs as a fraction of GDP (i.e. $\frac{g}{f}$ ) to be $2.3 \%$ of output. This appears to be reasonable, as will be discussed below.

The second row reports the marginal costs of hiring (i.e. $g_{v}$ ) in terms of average output per worker $\left(\frac{f}{n}\right)$. The reported value, 1.48 (value at sample mean point), is roughly equivalent to two quarters of wage payments, as wages are 0.66 of output per worker on average (see Table 1). How does one evaluate this estimate? There is little empirical evidence on the quantitative importance of such adjustment costs. There are, however, a few surveys of broad groups of employers on some of the costs of hiring. According to Hamermesh (1993, pp. 207-209), the findings are as diverse as are the groups studied or the concepts underlying the measurement. Thus, expressed in 1990

\footnotetext{
${ }^{8}$ Each adjustment cost term $-\frac{g}{f}, \frac{g_{v}}{f / n}, \frac{g_{i}}{f / k}$ - is some function of $\frac{i_{t}}{k_{t}}$ and $\frac{q_{t} v_{t}}{n_{t}}$. The first reported expression is the cost evaluated at mean $\frac{i_{t}}{k_{t}}$ and mean $\frac{q_{t} v_{t}}{n_{t}}$. The second is the standard deviation, with the variables evaluated at the same mean point; this is computed using the variance-covariance matrix of the estimators.
} 
US dollars, the gross costs range from $\$ 680$ for hiring a secretary by a large employer in 1979 to $\$ 13,790$ for hiring and training salaried workers in Los Angeles in 1980. Similarly, for a large pharmaceutical company the costs of training and career development range from 1.5 to 2.5 times the annual salary. Note that none of those surveys attempts to account for the costs of disruption to the flow of output. Note too, that almost all other studies on labor adjustment costs typically pertain to costs of net employment changes (i.e. $n_{t}-n_{t-1}$, as distinct from gross hiring $q_{t} v_{t}$ ). Hence, there is no solid benchmark against which to compare the current estimates, and what can be said is that the above estimate appears plausible.

The third row reports the marginal costs of investment (i.e. $g_{i}$ ) in terms of average output per unit of capital $\left(\frac{f}{k}\right) .{ }^{9}$ The estimate is 1.31 for marginal costs at the the mean point.

How reasonable are these estimates? There is no simple comparison that can be made, once some modelling and computational issues are recognized. The most natural place to look for comparisons is the Q-literature. Table 5 shows some estimates of the investment equation from this literature. The equation links the investment-to-capital ratio to a measure of Tobin's Q. Note that these studies differ from each other and from the current study on many dimensions: the data sample used, the functional form assumed for marginal adjustment costs $(M C)$, additional variables included in $M C$, treatment of tax issues, and reduced form vs. structural estimation. Estimates of the curvature of the marginal cost function may be conditional on additional variables included in the analysis; reduced form estimates may be consistent with several alternative underlying structural models. The studies often came in response to previous estimates, each trying to introduce changes so as to improve on the previous ones; some of these changes were substantial. Hence, Table 5 cannot give more than a very rough idea as to the "neighborhood" of adjustment costs estimates.

\footnotetext{
${ }^{9}$ The units of measurement - in terms of output per unit of capital - were chosen so as to facilitate comparison with existing studies, as discussed below.
} 
Panel (a) of the table shows large variation across studies: it ranges from marginal costs as low as 0.02 to as high as 9.5 or, put differently, estimates of the adjustment cost parameter in a linear formulation (i.e. $\gamma$ in $\gamma \frac{I}{K}$ ) ranging from 0.15 to 53 . It should be noted that the differences in marginal cost estimates are usually due to differences in the parameter estimates, and not just due to the diversity in the rate of investment used.

Panel (b) takes key values from panel (a) and computes total adjustment costs as a fraction of output $\left(\frac{T C}{F}\right)$ and marginal costs as a fraction of output per unit of capital $\left(\frac{M C}{\frac{F}{K}}\right)$. It takes the quadratic specification used in most studies (i.e. $T C=\frac{\gamma}{2}\left(\frac{I}{K}\right)^{2} K$ ) and evaluates these measures of costs at the two values of $\frac{I}{K}-0.10$ or 0.20 - that feature prominently in panel (a). It computes the relevant value of $\frac{F}{K}$ assuming either $\frac{I}{F}=0.15$ or $\frac{I}{F}=0.20$ which are standard values, in line with macroeconomic data. The panel presents these computations within three sets:

(i) Very high adjustment costs, as in studies $1,2,5 \mathrm{a}$, and $6 \mathrm{a}$, where $\gamma$ lies mostly between 20 and 50. Total costs thus range between $15 \%$ to $100 \%$ of output and marginal costs range between 3 to 10 in terms of average output per unit of capital. This set characterizes the earlier studies

(ii) Moderate adjustment costs, as in studies 3, 4, 5b, 6b, 7a, 7b and 8, where $\gamma$ lies mostly between 0.7 and 3 . Total costs range between $0.5 \%$ to $6 \%$ of output and marginal costs are 0.1 to 0.6 average output per unit of capital.

(iii) Low adjustment costs, as in studies 9 and 10, where $\gamma$ is between 0.1 and 0.3 . Panel (b) takes the value of $\gamma=0.2$ for which total costs range between $0.1 \%$ to $0.2 \%$ of output and marginal costs are 0.03 to 0.04 of average output per unit of capital.

Coming back to the initial question of comparing these estimates to our findings, two conclusions emerge:

(i) The specification that we run that is closest to the one used in most studies of Table 5 is the one reported in Table $3 . \quad$ Column 1 reports the results with essentially the same specification, i.e., positing a quadratic function and ignoring labor. Using the terminology of panel (b) of Table 5 , and referring back to Table 4 , the implied total costs are $4.2 \%$ of output, as in studies of the moderate adjustment costs set. The implied marginal costs are 3.55 of average output per 
unit of capital, as in the low part of the high adjustment costs results.

(ii) Our GMM results of the full model, i.e., the results reported in Table 2, cannot be directly compared to the results of Table 5, as they take into account hiring costs through the interaction between hiring and investment costs and have a convex specification. In formal terms our marginal investment costs are specified by $\frac{g_{i}}{\frac{f}{k}}=\left[f_{1}+e_{1}\left(\frac{i}{k}\right)^{\eta_{1}-1}+e_{3}\left(\frac{q v}{n}\right)^{\eta_{3}}\left(\frac{i}{k}\right)^{\eta_{3}-1}\right]$ while most specifications of Table 5 posit $g_{i}=\gamma \frac{i}{k}$. In particular, our expression depends on $\frac{q v}{n}$ in a substantial way. Nevertheless we can calculate total adjustment costs as a fraction of output $\left(\frac{T C}{F}\right)$ and marginal costs as a fraction of output per unit of capital $\left(\frac{M C}{\frac{F}{K}}\right)$ as in panel (b) of Table 5 . This computation is shown in the first and third rows of Table 4 . The implied total costs are $2.3 \%$ of output, which lies within the low part of the moderate adjustment costs set. The implied marginal costs are 1.31 of average output per unit of capital, somewhat higher than the moderate adjustment costs range.

We thus conclude that while the quadratic specification (with no hiring costs) yields high marginal adjustment costs, the preferred specification, with hiring costs and interaction of investment and hiring, yields relatively moderate adjustment costs.

Note, too, in Table 4 that adjustment costs - both total and marginal - are estimated relatively precisely (compare the standard deviation to the value at the mean point).

\subsection{Performance of the Estimated Optimality Equations}

The estimated equations $(F 1)$ and $(F 2)$ determine the firms' optimal investment and hiring behavior. In the preceding sub-section we have seen that the point estimates imply reasonable values for the adjustment costs function, which is the object of estimation in these equations. To further evaluate the performance of the estimated equations, Figure 1 provides a plot of the equations errors (see equations 10.2 and 10.3 in Appendix C below) and some statistics testing for auto-correlation. 
The graphs and statistics point to a relatively good fit; in $F 1$ there is some small negative auto-correlation, and in $F 2$ there is no autocorrelation.

\subsection{Joint Behavior of Hiring and Investment}

Across all specifications, the estimate of the coefficient of the interaction term, $e_{3}$, is negative. This negative point estimate implies a negative value for $g_{v i}$ and, therefore, a positive sign for $\partial \frac{q_{t} v_{t}}{n_{t}} / \partial Q^{k}$ and for $\partial \frac{i_{t}}{k_{t}} / \partial Q^{n}$ (for the full derivation see Appendix D.) Note that evidently $\partial \frac{i_{t}}{k_{t}} / \partial Q^{k}$ and $\partial \frac{q_{t} v_{t}}{n_{t}} / \partial Q^{n}$ are positive due to convexity. Hence, when the marginal value of investment $Q^{K}$ rises, both the investment rate $\frac{i}{k}$ and the hiring rate $\frac{q v}{n}$ rise. A similar argument shows that when the marginal value of hiring $Q^{N}$ rises, both $\frac{i}{k}$ and $\frac{q v}{n}$ rise. Put differently, this result states that for given levels of investment, total and marginal costs of investment decline as hiring increases. Similarly, for given levels of hiring, total and marginal costs of hiring decline as investment increases. This finding is to be expected as it implies simultaneous hiring and investment. One interpretation of this result is that simultaneous hiring and investment is less costly than sequential hiring and investment of the same magnitude. This may be due to the fact that simultaneous action by the firm is less disruptive to production than sequential action.

The following distinction, however, is important. The afore-going argument favors simultaneous hiring and investment, i.e., positive levels of both $\left(\frac{i}{k}, \frac{q v}{n}>0\right)$. Thus the representative firm is hiring and investing at the same time. But it does not necessarily imply positive co-movement or correlation between hiring and investment (i.e. $\rho\left(\frac{i}{k}, \frac{q v}{n}\right) \lessgtr 0$ ). In other words investment and hiring take place at the same time, but it is possible to have one rise while the other declines. When will that happen? Using (11.1) below, one can see that if $Q^{K}$ rises and $Q^{N}$ declines at the same time, then the rise in $Q^{K}$ will lead to higher investment and higher hiring, while the fall in $Q^{N}$ will lead to lower investment and lower hiring. If the effect of $Q^{K}$ on investment and the effect of $Q^{N}$ on hiring are dominant (respectively), then investment would rise and hiring would fall. In other words this may be a case of negative correlation between hiring and investment. Thus, hiring 
and investment may move in opposite directions even when $e 3$ is negative.

Table 6 reports the sample correlation between hiring and investment, between the estimated $Q_{K}$ and $Q_{N}$, using the results of Table 2, and other correlations between these variables.

The main features standing out from the table are that in the sample period investment and hiring rates were negatively correlated, as were $Q_{t}^{K}$ and $Q_{t}^{N} ; Q_{t}^{K}$ was positively correlated with the investment rate $\frac{i_{t}}{k_{t}}$ and negatively correlated with the hiring rate $\frac{q_{t} v_{t}}{n_{t}}$; similarly $Q_{t}^{N}$ was positively correlated with hiring rate $\frac{q_{t} v_{t}}{n_{t}}$ and negatively correlated with the investment rate $\frac{i_{t}}{k_{t}}$. These results are consistent with the above explanation and the idea that the effect of $Q^{K}$ on investment and the effect of $Q^{N}$ on hiring are dominant. This implies that driving factors pushed asset values $\left(Q_{t}^{K}\right.$ and $Q_{t}^{N}$ ) in different directions and, consequently, the investment rate $\frac{i_{t}}{k_{t}}$ and the hiring rate $\frac{q_{t} v_{t}}{n_{t}}$, while simultaneously positive, moved in different directions.

\section{Explaining Asset Values}

In this section we derive the implications of the estimates for market asset values. We look at the model's fit of the data (6.1), decompose the estimated market value into components due to capital and investment and due to labor and hiring (6.2), and give an interpretation of the results (6.3).

\subsection{The Model's Fit}

The estimates allow us to generate predicted time series of asset values. ${ }^{10}$ We use the formulation of the asset pricing equation using only time $t$ variables (see Appendix $\mathrm{C}$ for a full derivation):

\footnotetext{
${ }^{10}$ This can be done in two ways. One is described in the text below. The other uses the RHS of equation (2.20) without the expectation error, i.e.:

$$
\left(\frac{s_{t}}{f_{t}}\right)-j_{t}^{3}=\frac{f_{t+1}}{f_{t}}\left[\begin{array}{c}
\frac{1}{\frac{f_{t+1}}{k_{t+1}}}\left\{\beta_{t+1}\left(1-\tau_{t+1}\right)\left[f_{k_{t+1}}-g_{k_{t+1}}+\left(1-\delta_{t+1}\right)\left(p_{t+1}^{I}+g_{i_{t+1}}\right)\right]\right\} \\
+\frac{1}{\frac{f_{t+1}}{n_{t+1}}}\left\{\beta_{t+1}\left(1-\tau_{t+1}\right)\left(f_{n_{t+1}}-g_{n_{t+1}}-w_{t+1}+\left(1-\psi_{t+1}\right) \frac{g_{v_{t+1}}}{q_{t+1}}\right)\right\}
\end{array}\right]
$$
}




$$
\begin{aligned}
\frac{s_{t}}{f_{t}}= & {\left[\left(1-\delta_{t}\right)+\frac{i_{t}}{k_{t}}\right]\left[\left(1-\tau_{t}\right)\left(\left[f_{1}+e_{1}\left(\frac{i_{t}}{k_{t}}\right)^{\eta_{1}-1}+e_{3}\left(\frac{q_{t} v_{t}}{n_{t}}\right)^{\eta_{3}}\left(\frac{i_{t}}{k_{t}}\right)^{\eta_{3}-1}\right]+\frac{p_{t}^{I}}{\frac{f_{t}}{k_{t}}}\right)\right] } \\
& +\left[\left(1-\psi_{t}\right)+\frac{q_{t} v_{t}}{n_{t}}\right]\left[\left(1-\tau_{t}\right)\left[f_{2}+e_{2}\left(\frac{q_{t} v_{t}}{n_{t}}\right)^{\eta_{2}-1}+e_{3}\left(\frac{i_{t}}{k_{t}}\right)^{\eta_{3}}\left(\frac{q_{t} v_{t}}{n_{t}}\right)^{\eta_{3}-1}\right]\right]+\xi_{t}
\end{aligned}
$$

We denote the entire expression on the RHS except for the error by $\widetilde{\left(\frac{s_{t}}{f_{t}}\right)}{ }^{t}\left[\right.$ i.e. $\frac{s_{t}}{f_{t}}={\widetilde{\left(\frac{s_{t}}{f_{t}}\right)}}^{t}+$ $\left.\xi_{t}\right]$

Figure 2 shows the actual series and the predicted $\widetilde{\left(\frac{s_{t}}{f_{t}}\right)^{t}}$. Table 7 reports the sample moments of the actual series and the predicted series and the correlations between them. The figure and table do this for the specification representative of Table 2 (column 7 ) as well as for the specifications of columns 1 and 2 of Table 3 .

The key result is that the preferred specification, using the full model, performs well; the widely-used quadratic with no hiring performs poorly; and the convex specification that does not allow for interaction between hiring and investment costs has mediocre performance. This can be seen on all dimensions of the analysis: the correlation statistics, the comparison of actual and predicted moments, and the graphs.

More specifically, all the moments of the predicted series based on the results of Table 2 are very close to the actual series, typically slightly lower. This applies to the first four moments, to the median, and to the autocorrelation. The correlation between the actual and predicted series is high.

How do these results compare with existing formulations in the literature? One way to gauge this is to compare to the specification of column 1 in Table 3 . This is the standard quadratic

It turns out that there is very little difference between the two predicted series, so we report the one described below in (6.1). 
formulation, without hiring, prevalent in the literature. This specification does badly: it is uncorrelated with the actual series, is much less volatile, less persistent, and its skewness does not resemble the positive skewness of the actual series. These results are in line with the discussion in the literature, which has reported a low fit with $\mathrm{Q}$ measures and substantial serial correlation remaining in the error term.

Another way to evaluate the results is to turn to the literature itself. The main paper that is comparable is Cochrane (1991), that is essentially the above model with no labor and with no structural estimation of the relevant parameters. It is thus a Q-type model geared to explain asset prices rather than investment. Cochrane (1991) discusses returns rather than price levels and gets the following key results for U.S. data in the period 1947-1987 (see his discussion on pages 223-225 and in particular Table I and Figure 2):

(i) A correlation of 0.24 between investment returns and stock returns.

(ii) With the same mean return, investment returns have a standard deviation of 3.42 ; stock returns have a standard deviation of 7.24 ; thus stock returns are twice as volatile as investment returns.

(iii) The first auto-correlation of investment returns is 0.45 compared to 0.11 autocorrelation of stock returns, i.e. investment returns are much more persistent.

These results are not directly comparable, but they suggest a weaker fit, in particular in matching the volatility and persistence of the actual series. Note, though, that our results do strengthen the basic approach suggested by Cochrane (1991), in the sense that market value is well explained by a production-based asset pricing model.

One key point of the current analysis is the incorporation of hiring costs and their interaction with investment costs. What is the contribution of this element to the fit? One indication was given by the above analysis of the poor performance of the specification that ignores hiring. Another indication is obtained by comparing the results to those of column 2 in Table 3 ; this specification does allow for hiring costs and does posit a more convex function (relative to the quadratic) but it does not allow for any interaction between the two kinds of costs. Table 7 and Figure 2 indicate 
that it performs better than the quadratic with no hiring costs, but it does not provide for a very good fit: its correlation is lower and it is much less volatile. This demonstrates the important role played by the interaction between the two types of costs.

\subsection{Decomposing Asset Values}

We turn to decompose asset values in order to examine the relative role played by capital and by labor, as follows:

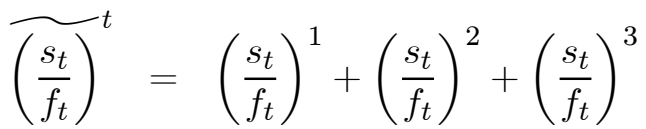

$$
\begin{aligned}
& \left(\frac{s_{t}}{f_{t}}\right)^{1}=\left[\left(1-\delta_{t}\right)+\frac{i_{t}}{k_{t}}\right]\left[\left(1-\tau_{t}\right) \frac{p_{t}^{I}}{\frac{f_{t}}{k_{t}}}\right] \\
& \left(\frac{s_{t}}{f_{t}}\right)^{2}=\left[\left(1-\delta_{t}\right)+\frac{i_{t}}{k_{t}}\right]\left[\left(1-\tau_{t}\right) \frac{g_{i_{t}}}{\frac{f_{t}}{k_{t}}}\right] \\
& \left(\frac{s_{t}}{f_{t}}\right)^{3}=\left[\left(1-\psi_{t}\right)+\frac{q_{t} v_{t}}{n_{t}}\right]\left[\left(1-\tau_{t}\right) \frac{\frac{g_{v_{t}}}{q_{t}}}{\frac{f_{t}}{n_{t}}}\right]
\end{aligned}
$$

The first part $\left(\frac{s_{t}}{f_{t}}\right)^{1}$ reflects value without any adjustment costs. The other two parts represent the present value of investing $\left(\frac{s_{t}}{f_{t}}\right)^{2}$ and of hiring $\left(\frac{s_{t}}{f_{t}}\right)^{3}$. While they are not priced on the market, the structural estimates allow for their quantification.

We present the decomposition in Table 8, using the point estimates of the specification representative of Table 2 .

\section{See Table 8 (p.xxx)}

Panel (a) presents the sample average value of the different terms in the above decomposition. In terms of parameters, the purely neoclassical part, $\left(\frac{s_{t}}{f_{t}}\right)^{1}$ depends only on the estimate of $\alpha$ (the labor coefficient in the production function) and on $p^{I}$. Hence, we can get an idea as to 
its magnitude even without the estimates of the $g$ function. Panel (b) computes this value out of actual $\left(\frac{s_{t}}{f_{t}}\right)$ for various plausible values of $\alpha$ and $p^{I}$. The results of panel (b) are consistent with the estimates of panel (a): over the whole sample the estimated share [in panel (a)] is 0.67, while the computed share in panel (b) lies between 0.50 and 0.75 . Hence, even with no estimates of the $g$ function, the above analysis implies that the value due to adjustment costs is about $33 \%$. In order to break down the latter into $\left(\frac{s_{t}}{f_{t}}\right)^{2}$ and $\left(\frac{s_{t}}{f_{t}}\right)^{3}$ we need to rely on the point estimates of Table 2 (column 7). The larger part turns out to be due to the value of hiring, $\left(\frac{s_{t}}{f_{t}}\right)^{3}$, at $22 \%$ of total asset value, while the value of investment $\left(\frac{s_{t}}{f_{t}}\right)^{3}$ accounts for $11 \%$ of total asset value on average.

Panel (c) shows the sample variance decomposition of $\widetilde{\left(\frac{s_{t}}{f_{t}}\right)}$. Each term is divided by the total variance so the elements of the matrix sum up to 1 . Once more it does not require estimates of the $g$ function to determine the relative share of the neoclassical part, $\left(\frac{s_{t}}{f_{t}}\right)^{1}$. Its share in the actual variance of $\frac{s_{t}}{f_{t}}$ is only 0.059 . Thus, the traditional part $\left(\frac{s_{t}}{f_{t}}\right)^{1}$ plays a very small role. Taken together with the fact, highlighted by Christiano and Fisher (2003), that $p^{I}$ was negatively correlated with $s$ in the sample period, this means that the traditional, neoclassical model cannot explain the time series behavior of asset values.

By far the biggest role in explaining the variance is played by the value of investment in capital. In fact, the value of investment in capital $\left(\frac{s_{t}}{f_{t}}\right)^{2}$ over-explains asset volatility, and so important contributions are the negative co-variation between the investment and hiring values $\left(\left(\frac{s_{t}}{f_{t}}\right)^{2}\right.$ and $\left.\left(\frac{s_{t}}{f_{t}}\right)^{3}\right)$ and between the neoclassical term and the investment value term $\left(\left(\frac{s_{t}}{f_{t}}\right)^{1}\right.$ and $\left.\left(\frac{s_{t}}{f_{t}}\right)^{2}\right)$. Note that the hiring value term $\left(\frac{s_{t}}{f_{t}}\right)^{3}$ exhibits substantial volatility, too. Thus, both adjustment costs are essential to account for market value volatility. The role played by hiring rates here is threefold: via the interaction term in $\left(\frac{s_{t}}{f_{t}}\right)^{2}$, via the hiring value term $\left(\frac{s_{t}}{f_{t}}\right)^{3}$, and via the covariance between $\left(\frac{s_{t}}{f_{t}}\right)^{2}$ and $\left(\frac{s_{t}}{f_{t}}\right)^{3}$. 


\subsection{Interpretation}

To gain some intuition with respect to these results in relation to standard formulations, consider again the asset pricing equation:

$$
s_{t}=k_{t+1} Q_{t}^{K}+n_{t+1} Q_{t}^{N} .
$$

In stationary form this can be re-written:

$$
\frac{s_{t}}{f_{t}}=\frac{f_{t+1}}{f_{t}}\left[\frac{Q_{t}^{K}}{\frac{f_{t+1}}{k_{t+1}}}+\frac{Q_{t}^{N}}{\frac{f_{t+1}}{n_{t+1}}}\right] .
$$

The basic problem in the literature has been to explain the behavior of $\frac{s}{f}$ which is highly auto-correlated (AR coefficient of 0.97) and highly volatile (coefficient of variation is 0.35 ). In the neoclassical model $Q^{K}=p^{I}, Q^{N}=0$. This implies that $\frac{s_{t}}{f_{t}}=\frac{f_{t+1}}{f_{t}} \frac{k_{t+1} p_{t}^{I}}{f_{t+1}}=\frac{k_{t+1} p_{t}^{I}}{f_{t}}$. The RHS of the latter is negatively correlated at -0.81 with actual $\frac{s}{f}$ and has much lower volatility - the coefficient of variation is 0.07 .

In the standard quadratic formulation of Tobin's Q, the expression on the RHS becomes $\frac{f_{t+1}}{f_{t}}\left[\frac{Q_{t}^{K}}{\frac{f_{t+1}}{k_{t+1}}}\right]$, where $Q_{t}^{K}$ is linear in $\frac{i_{t}}{k_{t}}$. This is the specification of Table 3, column 1. As seen in Table 7 , it is basically uncorrelated with $\frac{s_{t}}{f_{t}}$. The fitted series in this case too has a very low coefficient of variation (0.04).

The current formulation performs much better as it has four new ingredients: first, it includes the labor term $n_{t+1} Q_{t}^{N}$; second, the present value expressions $Q_{t}^{K}$ and $Q_{t}^{N}$ are convex functions of gross investment and gross hiring $\left(\frac{i_{t}}{k_{t}}\right.$ and $\left.\frac{q_{t} v_{t}}{n_{t}}\right)$ with a sufficiently high degree of convexity; third, gross hiring $\frac{q_{t} v_{t}}{n_{t}}$ is a volatile series (much more than net hiring $\frac{n_{t+1}-n_{t}}{n_{t}}$ ); fourth, there is a negative interaction between hiring and investment. These features generate the fit both in terms of correlation and in terms of volatility. Taking into account the value of labor, using the appropriate convexity, using gross rather than net flows, and taking into account the interaction between hiring and investment are thus crucial for explaining the dynamics of asset values. 


\section{Conclusions}

The paper embeds frictional labor markets and capital adjustment costs in a production-based asset pricing model, focusing on the relationship between labor and the market value of the firm. The model is corroborated using structural estimation with aggregate time-series data for the U.S. non-financial corporate business sector. Estimation, focusing on frictions and adjustment costs parameters, yields reasonable values for these costs. We find that the conventional specification quadratic adjustment costs for capital and no hiring costs - performs poorly. Rather, the interaction between capital and labor adjustment costs is important and non-linearities matter.

More specifically, the main empirical results can be summarized as follows:

(i) A convex adjustment costs function is able to account for the data, as evidenced by the $F 1$ and $F 2$ errors analysis and by the measures of fit of the predicted $\frac{s}{f}$. The latter performs much better than the prevalent quadratic specification.

(ii) Restricting the same equations to standard formulations (quadratic, ignoring hiring, or ignoring the investment-hiring interaction) yields poor performance.

(iii) The estimates imply adjustment costs of reasonable magnitude, both when compared to known estimates and when evaluated in terms of the breakdown of $\frac{s}{f}$ into components.

(iv) The present value of hiring $Q^{N}$ plays an important role both in terms of mean asset values and in terms of explaining asset value volatility.

(v) The fit of the model and its improvement over the existing literature is due to the use of gross flows for both investment and hiring, the joint consideration of hiring and investment including their interaction, and the sufficient convexity of the adjustment costs function.

The key implication of the results is that firms' market value embodies the value of hiring and investment over and above the capital stock. Investment and hiring asset values are forwardlooking, expected present value expressions. Consequently they exhibit relatively high volatility, similar to the behavior of financial variables with an asset value nature. The paper's key theme is to link a major financial variable - the market value of firms - to these asset values. The standard 
neoclassical model links this market value with a stock - namely capital - that does not have such properties. This difference explains the fact that the current model is able to account for the high volatility of firms' market value and to provide an empirically credible link between financial markets and the markets for physical capital and labor.

This paper does not attempt to characterize the driving impulses affecting hiring, investment and firms' market values. Further exploration of these forces, such as changes in productivity, is a natural next step. Such an investigation will require a general equilibrium setup. ${ }^{11}$ As shown in previous studies, this involves dealing with the consumption side and all the associated empirical difficulties. Another potential exploration is a micro study using firm-level data. Such a study could allow for firm or worker heterogeneity and the examination of issues such as fixed costs. However, a serious empirical difficulty lies in the (non) existence of appropriate data on gross worker flows in conjunction with consistent data on investment flows and firms' market value. Given that the interaction of hiring and investment rates has been shown to be important, this data problem needs to be resolved before any empirical exploration at the firm-level can be accomplished.

\footnotetext{
${ }^{11}$ The standard set-up will need to be changed to account for investment and hiring decisions of the type examined here; see, for example the discussion in Danthine and Donaldson (2002b).
} 


\section{References}

[1] Bleakley, Hoyt, Ann E. Ferris, and Jeffrey C. Fuhrer 1999. "New Data on Worker Flows During Business Cycles," New England Economic Review July-August, 49-76.

[2] Chirinko, Robert S. 1993. "Business Fixed Investment Spending: Modeling Strategies, Empirical Results, and Policy Implications," Journal of Economic Literature XXXI:1875-1911.

[3] Christiano, Lawrence J. and Jonas D.M. Fisher 2003. "Stock Market and Investment Good Prices: Implications for Macroeconomics," NBER Working Paper no. 10031.

[4] Cochrane, John H. 1991. "Production-Based Asset Pricing and the Link Between Stock Returns and Economic Fluctuations," Journal of Finance 146:207-234.

[5] ______ 1996. "A Cross-Sectional Test of an Investment-Based Asset Pricing Model," Journal of Political Economy 104:572-621.

[6] Cooper, Russell and John Haltiwanger 2005." On the Nature of Capital Adjustment Costs," available online at http://www.eco.utexas.edu/ cooper/.

[7] Cooper, Russell and Jonathan Willis 2003. "The Cost of Labor Adjustment: Inferences from the Gap," NBER Working Paper no. 10006.

[8] Danthine, Jean-Pierre and John B. Donaldson 2002a. "Labour Relations and Asset Returns," Review of Economic Studies 69:41-64.

[9] _ _ _ _ and Columbia University working papers.

[10] Denton, Frank T. 1971. "Adjustment of Monthly or Quarterly Series to Annual Totals: An Approach Based on Quadratic Minimization," Journal of the American Statistical Association 66:99-102. 
[11] Fama, Eugene F. and Kenneth R. French 1999. "The Corporate Cost of Capital and the Return on Corporate Investment," Journal of Finance LIV:1939-1967.

[12] Hall, Robert E. 2001. "The Stock Market and Capital Accumulation," American Economic Review 91:1185-1202.

[13] Hamermesh, Daniel S. 1993. Labor Demand, Princeton (Princeton University Press).

[14] Hansen, Lars P. 1982. "Large Sample Properties of Generalized Method of Moments Estimators," Econometrica 50:1029-1054.

[15] Hayashi, Fumio 1982. "Tobin's Marginal q and Average q: A Neoclassical Interpretation," Econometrica 50:213-224.

[16] Herman, Shelby 2000. "Fixed Assets and Consumer Durable Goods," Survey of Current Business, Bureau of Economic Analysis, Department of Commerce, April, 17-30.

[17] Mortensen, Dale. T. and Christopher A. Pissarides 1999. "Job Reallocation, Employment Fluctuations, and Unemployment Differences," Ch. 18 in John B. Taylor and Michael Woodford (eds.), Handbook of Macroeconomics, Vol. 1B, Amsterdam (North-Holland).

[18] Nadiri, M. Ishaq and Sherwin Rosen 1969. "Interrelated Factor Demand Functions," American Economic Review 59:457-471.

[19] Ogaki, Masao, Kyungho Jang, and Hyoung-Seok Lim 2005. Structural Macroeconometrics, manuscript, in preparation. Available online at http://www.kjang.com/book2003/.

[20] Pissarides, Christopher A. 2000. Equilibrium Unemployment Theory, 2nd edition, Cambridge (MIT Press).

[21] Shapiro, Matthew D. 1986. "The Dynamic Demand for Capital and Labor," The Quarterly Journal of Economics 101:513-542 
[22] Shea, John 1997. "Instrument Relevance in Multivariate Linear Models: A Simple Measure," The Review of Economics and Statistics 79: 348-352.

[23] Tobin, James 1969. "A General Equilibrium Approach to Monetary Theory," Journal of Money, Credit, and Banking 1:15-29.

[24] Tobin, James and William Brainard 1977. "Assets Markets and the Cost of Capital," in B. Belassa and R.Nelson (eds.) Economic Progress, Private Values and Public Policies: Essays in Honor of William Fellner, Amsterdam ( North-Holland), 235-262.

[25] Yashiv, Eran 2000. "The Determinants of Equilibrium Unemployment," American Economic Review 90:1297-1322. 


\section{Appendix A: Derivation of the Firms' Market Value Equation}

The following derivations are based on Hayashi (1982). First we multiply throughout the FONC with respect to investment (2.10) by $i_{t}$, the FONC with respect to capital (2.9) by $k_{t+1}$, the FONC with respect to vacancies (2.12) by $v_{t}$, and the one with respect to employment (2.11) by $n_{t+1}$ to get

$$
\begin{aligned}
0 & =-\left(1-\tau_{t}\right)\left(p_{t}^{I}+g_{i_{t}}\right) i_{t}+i_{t} Q_{t}^{K} \\
0 & =-\left(1-\tau_{t}\right) g_{v_{t}} v_{t}+v_{t} q_{t} Q_{t}^{N} \\
k_{t+1} Q_{t}^{K} & =k_{t+1} E_{t}\left\{\beta_{t+1}\left[\left(1-\tau_{t+1}\right)\left(f_{k_{t+1}}-g_{k_{t+1}}\right)+\left(1-\delta_{t+1}\right) Q_{t+1}^{K}\right]\right\} \\
n_{t+1} Q_{t}^{N} & =n_{t+1} E_{t}\left\{\beta_{t+1}\left[\left(1-\tau_{t+1}\right)\left(f_{n_{t+1}}-g_{n_{t+1}}-w_{t+1}\right)+\left(1-\psi_{t+1}\right) Q_{t+1}^{N}\right]\right\}
\end{aligned}
$$

We then insert the law of motion for capital (2.2) into equation (8.1), roll forward all expressions one period, multiply both sides by $\beta_{t+1}$ and take conditional expectations on both sides:

$$
E_{t}\left[\beta_{t+1}\left(1-\tau_{t+1}\right)\left(p_{t+1}^{I}+g_{i_{t+1}}\right) i_{t+1}\right]=E_{t}\left\{\beta_{t+1}\left[k_{t+2}-\left(1-\delta_{t+1}\right) k_{t+1}\right] Q_{t+1}^{K}\right\} .
$$

and so:

$$
E_{t}\left[\beta_{t+1}\left(1-\delta_{t+1}\right)\left(k_{t+1} Q_{t+1}^{K}\right)\right]=E_{t}\left\{\beta_{t+1}\left[\left(k_{t+2} Q_{t+1}^{K}-\left(1-\tau_{t+1}\right)\left(p_{t+1}^{I}+g_{i_{t+1}}\right) i_{t+1}\right)\right]\right\}
$$

Combining the last expression with equation (8.3) we get

$$
k_{t+1} Q_{t}^{K}=E_{t}\left(\beta_{t+1}\left(c f_{t+1}^{k}+k_{t+2} Q_{t+1}^{K}\right)\right)
$$

or

$$
E_{t}\left(\beta_{t+1} c f_{t+1}^{k}\right)=k_{t+1} Q_{t}^{K}-E_{t}\left(\beta_{t+1} k_{t+2} Q_{t+1}^{K}\right) .
$$

It follows from the definition of the firm's market value in equation (2.18) that

$$
\vartheta_{t}^{k}-E_{t}\left(\beta_{t+1} \vartheta_{t+1}^{k}\right)=E_{t}\left(\beta_{t+1} c f_{t+1}^{k}\right) .
$$


Thus,

$$
\vartheta_{t}^{k}-E_{t}\left(\beta_{t+1} \vartheta_{t+1}^{k}\right)=k_{t+1} Q_{t}^{K}-E_{t}\left(\beta_{t+1} k_{t+2} Q_{t+1}^{K}\right)
$$

which implies

$$
\vartheta_{t}^{k}=k_{t+1} Q_{t}^{K}
$$

We derive a similar expression for the case of labor. Inserting the law of motion for labor from equation (2.3) into equation (8.2), multiplying both sides by $\beta_{t}$, rolling forward all expressions by one period, taking conditional expectations, and combining with equation (8.4) we get

$$
E_{t}\left(\beta_{t+1} c f_{t+1}^{n}\right)=n_{t+1} Q_{t}^{N}-E_{t}\left(\beta_{t+1} n_{t+2} Q_{t+1}^{N}\right)
$$

The definition of the firm's value in equation (2.6) implies that

$$
\vartheta_{t}^{n}-E_{t}\left(\beta_{t+1} \vartheta_{t+1}^{n}\right)=E_{t}\left(\beta_{t+1} c f_{t+1}^{n}\right)
$$

Thus,

$$
\vartheta_{t}^{n}-E_{t}\left(\beta_{t+1} \vartheta_{t+1}^{n}\right)=n_{t+1} Q_{t}^{N}-E_{t}\left(\beta_{t+1} n_{t+2} Q_{t+1}^{N}\right) .
$$

This implies the following expression for the asset value of employment:

$$
\vartheta_{t}^{n}=n_{t+1} Q_{t}^{N}
$$

Hence, the total market value of a firm, $s_{t}$, equals:

$$
s_{t}=\vartheta_{t}^{k}+\vartheta_{t}^{n}=k_{t+1} Q_{t}^{K}+n_{t+1} Q_{t}^{N}
$$

where $Q_{t}^{K}$ and $Q_{t}^{N}$ are defined in equations (2.15) and (2.16), respectively. 


\section{Appendix B: The Data}

The data are quarterly and cover the period from 1976:1 to 2002:4. They pertain to the U.S. non-financial corporate business (NFCB) sector unless noted otherwise.

\subsection{Output and Price Deflator}

Output, $f$ and its price deflator $p^{f}$ pertain to the NFCB sector. They originate from the NIPA accounts published by the BEA of the Department of Commerce. ${ }^{12}$

\subsection{Investment, Capital, Depreciation and the Price of Investment}

We generate quarterly series by combining data series from the BEA and from the Flow of Funds Accounts of the Board of Governors. We depart from quarterly data whenever they are available. Our procedure to generate the quarterly series consists of two steps. Since we require all quarterly series to be consistent with the respective annual series, we start by putting together the annual series against which to compare the quarterly series.

\subsubsection{Step 1: Generating quarterly investment and depreciation series.}

a. We use the end-of-year stock of real physical capital $k$ from the BEA's fixed assets tables 4.1 and 4.2 and the annual real capital depreciation $k d e p r$ from the fixed assets table 4.4 in order to compute an implied annual investment series $i$ against which we later compare the quarterly series for consistency. ${ }^{13}$

$$
i_{t}=k_{t}-k_{t-1}+k d e p r_{t}
$$

\footnotetext{
${ }^{12}$ See www.bea.doc.gov/bea/dn/st-tabs.htm

${ }^{13}$ Note that we use the implied annual investment series, rather than the annual series from the BEA's Fixed Assets Tables (4.7 and 4.8), since the latter series systematically falls short of the implied series, and, therefore, cannot be used to replicate the annual capital stock data.
} 
The timing results from the fact that $k$ is an end-of-year stock, whereas $k d e p r$ is a flow variable, so that the following link to the annual depreciation rate $\delta$ holds:

$$
k d e p r_{t}=\delta_{t} \cdot k_{t-1}
$$

We compute the real quarterly investment series using the nominal quarterly investment series from table F.6 of the Flow of Funds Accounts of the Board of Governors of the Federal Reserve, deflating it by the price index of nonresidential private fixed investment (NIPA table 1.1.5). ${ }^{14}$

Since the implied annual real investment series $i$ from BEA is typically different than the time-aggregate of the quarterly real investment series from the Flow of Funds Accounts, we use Denton's (1971) method in order to equally spread the discrepancy between these two series across the quarterly entries of any given year. ${ }^{15}$

b. To generate quarterly real depreciation rates, $\delta_{q}$, we divide the quarterly real series on capital depreciation in NFCB from NIPA table 1.14 by a quarterly real series on physical capital which we simulate by log-linearly interpolating the annual figures on physical capital from the fixed assets tables 4.1 and 4.2 .

We can show that for the simulated quarterly capital series to be compatible with the annual capital series, the implied annual investment series $i$ needs to equal the following expression

$$
i_{1}\left(1-\delta_{q, 1}\right)\left(1-\delta_{q, 2}\right)\left(1-\delta_{q, 3}\right)+i_{2}\left(1-\delta_{q, 2}\right)\left(1-\delta_{q, 3}\right)+i_{3}\left(1-\delta_{q, 3}\right)+i_{4}
$$

where $i_{t}, t=1,2,3,4$ denotes investment in quarter $t$.

With quarterly capital depreciation, expression (9.1) typically falls short of the annual investment

\footnotetext{
${ }^{14}$ We built an alternative investment deflator using annual real and nominal data on investment in NFCB from the BEA's fixed assets tables 4.7 and 4.8 and log-linearly interpolated it. The correlation coefficient between the two alternative deflators equals 0.994 between 1973:1 and 2001:4. Since the latter deflator is not available beyond 2001, we work with the deflator based on nonresidential private fixed investment.

${ }^{15}$ This spread can be uniform, or it can follow a more involved pattern. We used a more involved pattern, but the results were very similar when we used the most simple distributive scheme.
} 
$i$, and hence, the aggregated quarterly capital series falls short of its annual pendant. We therefore equally spread any discrepancy between the implied annual investment series $i$ and expression (9.1) across the respective quarters by applying Denton's (1971) method again.

\subsubsection{Step 2: Generating quarterly capital stock series.}

We use the twice adjusted quarterly real investment series, the quarterly real depreciation rate, a starting value for the real physical capital stock and simulate the desired quarterly series of real physical capital with the help of the well-known capital accumulation equation:

$$
k_{t+1}=k_{t}\left(1-\delta_{t}\right)+i_{t} .
$$

The end-of-year values of the quarterly series are very close to the corresponding values of the annual series from the fixed assets tables 4.1 and 4.2 .

\subsubsection{Real Price of New Capital Goods}

In order to compute the real price of new capital goods, $p^{I}$, we determine the price indices for output and for investment goods. The price index for output, $p^{f}$, equals the ratio of nominal to real GDP in NFCB. We know that investment in NFCB Inv consists of the components equipment $E q$ and structures $S t$. We define the time-t price-indices for good $j=I n v, E q, S t$ as $p_{t}^{j}$ respectively and their change between $\mathrm{t}-1$ and $\mathrm{t}$ by $\Delta p_{t}^{j}, j=I n v, E q$, St. These price indices are chain-weighted. Thus, we know that

$$
\frac{\Delta p_{t}^{I n v}}{p_{t-1}^{I n v}}=\omega_{t} \frac{\Delta p_{t}^{E q}}{p_{t-1}^{E q}}+\left(1-\omega_{t}\right) \frac{\Delta p_{t}^{S t}}{p_{t-1}^{S t}}
$$

where

$\omega_{t}=\frac{(\text { nominal expenditure share of } E q \text { in } I n v)_{t-1}+(\text { nominal expenditure share of } E q \text { in } I n v)_{t}}{2}$. 
We start from an arbitrary value $p_{0}^{I n v}$ and construct the sequence of prices indices $\left\{p_{t}^{I n v}\right\}_{t=0}^{T}$ by adding the percentage changes computed from the equations above. Finally, we divide the series by the price index for output, $p_{t}^{F}$, to obtain the relative price of new capital goods, $p^{I}$.

Note that the price indices $p^{E q}$ and $p^{S t}$ and therefore $p^{I}$ are actually adjusted for taxes. Let the parameter $\tau$ denotes the statutory corporate income tax rate as reported by the U.S. Tax Foundation. Let ITC denote the investment tax credit on equipment and public utility structures, $Z P D E$ the present discounted value of capital depreciation allowances, and $\chi$ the percentage of the cost of equipment that cannot be depreciated if the firm takes the investment tax credit. ${ }^{16}$ Then

$$
\begin{aligned}
p^{E q} & =\widetilde{p}^{E q}\left(1-\tau_{E q}\right), p^{S t}=\widetilde{p}^{S t}\left(1-\tau_{S t}\right), \\
\tau^{E q} & =\frac{(1-\tau Z P D E)}{1-\tau} \\
\tau^{S} & =\frac{1-I T C-\tau Z P D E(1-\chi I T C)}{1-\tau}
\end{aligned}
$$

Finally, as $p_{t}^{I}$ is an index, we multiply it by a positive scaling constant $e^{A}$ where we either impose or estimate $A$.

\subsection{Employment, Matches and Separations}

Employment $n$ is defined as wage and salary workers in non-agricultural industries less government workers less workers in private households less self-employed workers less unpaid family workers. All series originate from the BLS.

For matches $(q v)$ and separation $(\psi)$ we use data on gross worker flows as computed by Bleakely et al. (1999). These data are adjusted, including seasonal adjustment, in ways explained

\footnotetext{
${ }^{16}$ The last three series are the ones compiled for the macro model of the Board of Governors of the U.S. Federal Reserve System. Flint Brayton kindly provided us with these series.
} 
in the latter reference. They pertain to flows between the employment pool on the one hand and the unemployment and out of the labor force pools on the other hand.

This data set pertains to the entire economy. In most specifications we wish to consider flows pertaining to the non-financial corporate sector. We thus proceed as follows:

a. Denoting variables for the entire economy by TOT we solve for $\psi^{T O T}$ period by period from the labor force dynamics equation:

$$
n_{t+1}^{T O T}=n_{t}^{T O T}\left(1-\psi_{t}^{T O T}\right)+(q v)_{t}^{T O T}
$$

b. We then use the dynamic equation to solve for $(q v)^{N F C B}$ (where $N F C B=$ non financial corporate business) period by period as follows:

$$
n_{t+1}^{N F C B}=n_{t}^{N F C B}\left(1-\psi_{t}^{T O T}\right)+(q v)_{t}^{N F C B}
$$

In estimation we use $\frac{(q v)_{t}^{N F C B}}{n_{t}^{N F C B}}$ and $\psi_{t}^{T O T}$. Thus we are implicitly assuming - for lack of data - that $\psi_{t}^{T O T}=\psi_{t}^{N F C B}$ but we are not imposing such restrictions on $(q v)_{t}^{N F C B}$ on which we do not have data directly.

In Table C-3 we use two alternatives. Column 6 solves $(q v)_{t}^{N F C B}$ from the following equation:

$$
n_{t+1}^{N F C B}=n_{t}^{N F C B}\left(1-\psi_{t}^{T O T, a c t u a l}\right)+(q v)_{t}^{N F C B}
$$

Here we use the actual separation rate for the entire economy $\psi_{t}^{\text {TOT,actual }}$.

In column 7 of that table we use $\frac{(q v)_{t}^{T O T}}{n_{t}^{T O T}}$ and $\psi_{t}^{T O T}$ i.e. values for the entire economy rather than just the corporate sector.

\subsection{The Labor Share}

For the labor share of income $\frac{w n}{f}$ we use compensation of employees (the sum of wage and salary accruals and supplements to wages and salaries) as a fraction of the gross product of the non- 
financial corporate business sector. ${ }^{17}$

\subsection{Market Value Data}

We use the market value of non-farm, non-financial business. The data originate from Hall (2001). ${ }^{18}$ They are based on the Fed Flow of Funds accounts and are defined as follows.

Source: Flow of Funds data and interest rate data from www.federalreserve.gov/releases. The data are for non-farm, non-financial business. Stock data were taken from ltabs.zip. ${ }^{19}$

Definition: The value of all securities is the sum of financial liabilities and equity less financial assets, adjusted for the difference between market and book values for bonds. ${ }^{20}$

\subsection{Discount Rate and Discount Factor}

We use four alternatives for the firms' discount rate $r_{t}$, which generates the discount factor given by $\beta_{t}=\left[1 /\left(1+r_{t}\right)\right]$ :

a. The main series used, following the weighted average cost of capital approach in corporate finance, is a weighted average of the returns to debt, $r_{t}^{b}$, and equity, $r_{t}^{e}$ :

$$
r_{t}=\omega_{t} r_{t}^{b}+\left(1-\omega_{t}\right) r_{t}^{e}
$$

with

$$
\begin{aligned}
r_{t}^{b} & =\left(1-\tau_{t}\right) r_{t}^{C P}-\theta_{t} \\
r_{t}^{e} & =\frac{\widetilde{c f}}{\widetilde{s}_{t}}+\widetilde{\widehat{s}}_{t}-\theta_{t}
\end{aligned}
$$

where:

(i) $\omega_{t}$ is the share of debt finance as reported in Fama and French (1999).

\footnotetext{
${ }^{17}$ The data are taken from NIPA Table 1.16, lines 19 and 24.

${ }^{18}$ See www.stanford.edu/ rehall/Procedure.htm for a full description and www.stanford.edu/ rehall/page3.html.

${ }^{19}$ Downloaded at www.federalreserve.gov/releases/z1/Current/data.htm.

${ }^{20}$ The subcategories unidentified miscellaneous assets and liabilities were omitted from all of the calculations. These are residual values that do not correspond to any financial assets or liabilities.
} 
(ii) The definition of $r_{t}^{b}$ reflects the fact that nominal interest payments on debt are tax deductible. $r_{t}^{C P}$ is Moody's seasoned Aaa commercial paper rate. The commercial paper rate for the first month of each quarter represents the entire quarter. The tax rate is $\tau$ as discussed above.

(iii) $\theta$ denotes inflation and is measured by the GDP-deflator of $p^{f}$ discussed above.

(iv) For equity return we use the CRSP Value Weighted NYSE, Nasdaq and Amex nominal returns $\left(\frac{\widetilde{c f}}{\widetilde{s}_{t}}+\widetilde{\widehat{s}}_{t}\right.$ in terms of the model, using tildes to indicate nominal variables) deflated by the inflation rate $\theta$.

The above is computed quarterly using monthly returns of a given quarter. As an alternative we compute the quarterly returns using the monthly returns of months 2 and 3 within the same quarter and month 1 in the following quarter.

We experiment with two other series to see their effect on the results:

b. The rate of change of the SP500 index computed as follows:

$$
r_{t}^{Q}=\frac{\left[\frac{S_{3}}{S_{0}} \frac{S_{4}}{S_{1}} \frac{S_{5}}{S_{2}}\right]^{\frac{1}{3}}}{1+\vartheta}-1
$$

where $S_{j}$ is the level of the stock index at the end of month $l$, the current quarter has months 4 and 5 , the preceding quarter has months 1,2,3 and the quarter preceding that has month 0.

c. Non-durable consumption growth, which corresponds to the discount rate in a DSGE model with logarithmic utility. If utility is given by:

$$
U\left(c_{t}\right)=\ln c_{t}
$$

Then in general equilibrium:

$$
U^{\prime}\left(c_{t}\right)=U^{\prime}\left(c_{t+1}\right)\left(1+r_{t, t+1}\right)
$$

Hence:

$$
r_{t, t+1}=\frac{c_{t+1}}{c_{t}}-1
$$




\section{Appendix C: Estimation Methodology and Robustness Checks}

\subsection{GMM}

We use the GMM methodology proposed by Hansen (1982). ${ }^{21}$ The three equations to be estimated - the firms' first-order necessary conditions $(F 1)$ and $(F 2)$, and the asset pricing equation (2.20) — include the parameters of the adjustment costs function $g$ and the production function $f$. These parameters are estimated by using the property of rational expectations whereby the firm's expectational errors are uncorrelated with any variable in the firms' information set. Formally there is a set of orthogonality conditions involving the expectational error $j_{t}$ and a vector of instruments $\mathbf{Z}$ :

$$
E_{t}\left[\mathbf{Z}_{t} \otimes j_{t}\left(\mathbf{x}_{t+1}, \boldsymbol{\Theta}_{0}\right)\right]=0
$$

where $\mathbf{x}$ is a vector of variables, $\boldsymbol{\Theta}_{0}$ is a vector of parameters to be estimated, $\otimes$ is the Kronecker product operator and $\mathbf{Z}_{t}$ is a vector of elements in the firms' information set $\boldsymbol{\Omega}_{t}$.

\subsection{Estimating Equations}

Taking equations $(F 1)$ divided throughout by $\frac{f_{t}}{k_{t}},(F 2)$ divided throughout by $\frac{f_{t}}{n_{t}}$ and $(2.20)$ divided throughout by $f_{t}$ (to induce stationarity), and replacing expected values by actual ones, the errors $j_{t}$ are derived as follows:

$$
\begin{aligned}
& \left.j_{t}^{1}=\frac{\left(1-\tau_{t}\right)\left(g_{i_{t}}+p_{t}^{I}\right)}{\frac{f_{t}}{k_{t}}}-\left\{\frac{\frac{f_{t+1}}{k_{t+1}}}{\frac{f_{t}}{k_{t}}} \frac{\beta_{t+1}\left(1-\tau_{t+1}\right)}{\frac{f_{t+1}}{k_{t+1}}}\left[f_{k_{t+1}}-g_{k_{t+1}}+\left(1-\delta_{t+1}\right)\left(g_{i_{t+1}}+p_{t+1}^{I}\right)\right] 1\right\} .2\right) \\
& j_{t}^{2}=\frac{\left(1-\tau_{t}\right) \frac{g_{v_{t}}}{q_{t}}}{\frac{f_{t}}{n_{t}}}-\left\{\frac{\frac{f_{t+1}}{n_{t+1}}}{\frac{f_{t}}{n_{t}}} \frac{\beta_{t+1}\left(1-\tau_{t+1}\right)}{\frac{f_{t+1}}{n_{t+1}}}\left[f_{n_{t+1}}-g_{n_{t+1}}-w_{t+1}+\left(1-\psi_{t+1}\right) \frac{g_{v_{t+1}}}{q_{t+1}}\right]\right\} \quad(10.3) \\
& j_{t}^{3}=\frac{s_{t}}{f_{t}}-\frac{f_{t+1}}{f_{t}}\left[\begin{array}{c}
\frac{1}{\frac{f_{t+1}}{k_{t+1}}}\left\{\beta_{t+1}\left(1-\tau_{t+1}\right)\left[f_{k_{t+1}}-g_{k_{t+1}}+\left(1-\delta_{t+1}\right)\left(p_{t+1}^{I}+g_{i_{t+1}}\right)\right]\right\} \\
+\frac{1}{\frac{1}{n_{t+1}}}\left\{\beta_{t+1}\left(1-\tau_{t+1}\right)\left(f_{n_{t+1}}-g_{n_{t+1}}-w_{t+1}+\left(1-\psi_{t+1}\right) \frac{g_{v_{t+1}}}{q_{t+1}}\right)\right\}
\end{array}\right]
\end{aligned}
$$

\footnotetext{
${ }^{21}$ For elaboration on the methodology see Ogaki et al (2005).
} 
The functions and their derivatives are given by:

$$
\begin{aligned}
& f\left(z_{t}, n_{t}, k_{t}\right)=e^{z_{t}} n_{t}^{\alpha} k_{t}^{1-\alpha} \\
& f_{k_{t}}=(1-\alpha) \frac{f_{t}}{k_{t}} \\
& f_{n_{t}}=\alpha \frac{f_{t}}{n_{t}} \\
& g=\left[f_{1} \frac{i_{t}}{k_{t}}+f_{2} \frac{q_{t} v_{t}}{n_{t}}+\frac{e_{1}}{\eta_{1}}\left(\frac{i_{t}}{k_{t}}\right)^{\eta_{1}}+\frac{e_{2}}{\eta_{2}}\left(\frac{q_{t} v_{t}}{n_{t}}\right)^{\eta_{2}}+\frac{e_{3}}{\eta_{3}}\left(\frac{q_{t} v_{t}}{n_{t}} \frac{i_{t}}{k_{t}}\right)^{\eta_{3}}\right] f_{t} \\
& g_{i}=\left[f_{1}+e_{1}\left(\frac{i_{t}}{k_{t}}\right)^{\eta_{1}-1}+e_{3}\left(\frac{q_{t} v_{t}}{n_{t}}\right)^{\eta_{3}}\left(\frac{i_{t}}{k_{t}}\right)^{\eta_{3}-1}\right] \frac{f_{t}}{k_{t}} \\
& \frac{g_{v}}{q}=\left[f_{2}+e_{2}\left(\frac{q_{t} v_{t}}{n_{t}}\right)^{\eta_{2}-1}+e_{3}\left(\frac{i_{t}}{k_{t}}\right)^{\eta_{3}}\left(\frac{q_{t} v_{t}}{n_{t}}\right)^{\eta_{3}-1}\right] \frac{f_{t}}{n_{t}} \\
& g_{k}=-\left[f_{1} \frac{i_{t}}{k_{t}}+e_{1}\left(\frac{i_{t}}{k_{t}}\right)^{\eta_{1}}+e_{3}\left(\frac{q_{t} v_{t}}{n_{t}} \frac{i_{t}}{k_{t}}\right)^{\eta_{3}}\right] \frac{f_{t}}{k_{t}}+g(1-\alpha) \frac{f_{t}}{k_{t}} \\
& g_{n}=-\left[f_{2} \frac{q_{t} v_{t}}{n_{t}}+e_{2}\left(\frac{q_{t} v_{t}}{n_{t}}\right)^{\eta_{2}}+e_{3}\left(\frac{q_{t} v_{t}}{n_{t}} \frac{i_{t}}{k_{t}}\right)^{\eta_{3}}\right] \frac{f_{t}}{n_{t}}+g \alpha \frac{f_{t}}{n_{t}}
\end{aligned}
$$

\subsection{Instruments.}

For the instruments used in $\mathbf{Z}_{t}$ we undertake instrument relevance tests. We consider a number of instrument sets, which include lags of variables appearing in the equations. Table C-1 reports the instruments sets and the relevance tests: first, the F statistics from first stage regressions of each endogenous variable on the instrument set. As these statistics consider each endogenous variable in isolation, the table goes on to consider a measure that takes into account joint relevance of the instruments. This is the adjusted partial $R_{p}^{2}$ suggested by Shea (1997): for any given endogenous variable $X_{i}$ it is the squared correlation between (i) the component of $X_{i}$ orthogonal to the other endogenous variables $X_{j \neq i}$ and (ii) the component of $X_{i}$ 's projection on the instruments orthogonal to the projection of the other endogenous variables $X_{j \neq i}$ on the instruments. This statistic $R_{p}^{2}$ is corrected for degrees of freedom as follows: 


$$
\bar{R}_{p}^{2}=1-\frac{T-1}{T-n}\left(1-R_{p}^{2}\right)
$$

where $T$ is sample size and $n$ is the number of instruments.

\section{See Table C-1 (p.xxxii)}

The main findings are as follows:

(i) The set $\left\{c s t, \frac{i_{t-j}}{k_{t-j}}, \frac{q_{t-j} v_{t-j}}{n_{t-j}}, \frac{s_{t-j}}{f_{t-j}}\right\}$ - i.e. the set of lagged values of the endogenous control variables and the asset value - is highly relevant. This is so both according to the F statistics and to the adjusted partial $R_{p}^{2}$ statistics. However individually these variables are not relevant, when the endogenous variables are considered jointly (i.e. the $R_{p}^{2}$ values are low).

(ii) Another set which is relevant to a large extent, though less than the afore mentioned one, is the set of the model's exogenous variables $\left\{c s t, \beta_{t-j}, \tau_{t-j}, \psi_{t-j}, \delta_{t-j}, \frac{w_{t-j} n_{t-j}}{f_{t-j}}, \frac{f_{t-j}}{k_{t-j}}\right\}$; individually or in pairs the instruments are not very relevant.

(iii) The number of lags does not matter much.

The reasons why sub-sets of instruments are not as relevant as the full set are two fold: one is straightforward - there may be lower explanatory power for the sub-set relative to the full set (taking into account degrees of freedom), as can be seen in the first-stage F statistics. The second reason appears to play a bigger role here and is due to multi-collinearity of the "fitted" endogenous variables i.e. the multi-collinearity of the parts of the endogenous variables explained by the instruments. This multi-collinearity was found to be bigger in the sub-sets than in the full set.

\subsection{An alternative specification}

We can also estimate the relevant parameters using just the asset pricing equation at time $t$. This can be derived as follows. Start from the asset pricing equation (2.19) and insert the laws of motion 
of the state variables (2.2) and (2.3):

$$
\begin{aligned}
s_{t} & =k_{t+1} Q_{t}^{K}+n_{t+1} Q_{t}^{N} \\
& =\left[\left(1-\delta_{t}\right) k_{t}+i_{t}\right] Q_{t}^{K}+\left[\left(1-\psi_{t}\right) n_{t}+q_{t} v_{t}\right] Q_{t}^{N}
\end{aligned}
$$

Use the F.O.C (2.10) and (2.12) to replace $Q_{t}^{K}$ and $Q_{t}^{N}$ as follows:

$$
\begin{aligned}
s_{t}= & {\left[\left(1-\delta_{t}\right) k_{t}+i_{t}\right]\left[\left(1-\tau_{t}\right)\left(g_{i_{t}}+p_{t}^{I}\right)\right] } \\
& +\left[\left(1-\psi_{t}\right) n_{t}+q_{t} v_{t}\right]\left[\left(1-\tau_{t}\right) \frac{g_{v_{t}}}{q_{t}}\right]
\end{aligned}
$$

After some manipulation this equation can be expressed in the following stationary form:

$$
\begin{aligned}
\frac{s_{t}}{f_{t}}= & {\left[\left(1-\delta_{t}\right)+\frac{i_{t}}{k_{t}}\right]\left[\left(1-\tau_{t}\right) \frac{\left(g_{i_{t}}+p_{t}^{I}\right)}{\frac{f_{t}}{k_{t}}}\right] } \\
+ & {\left[\left(1-\psi_{t}\right)+\frac{q_{t} v_{t}}{n_{t}}\right]\left[\left(1-\tau_{t}\right) \frac{\frac{g_{v_{t}}}{q_{t}}}{\frac{f_{t}}{n_{t}}}\right] }
\end{aligned}
$$

In order to be meaningful for estimation an error process needs to be specified. One way is to postulate that there is a stochastic element in asset values - to be denoted by $\xi_{t}$. Hence the period $t$ estimating equation is:

$$
\begin{aligned}
\frac{s_{t}}{f_{t}}= & {\left[\left(1-\delta_{t}\right)+\frac{i_{t}}{k_{t}}\right]\left[\left(1-\tau_{t}\right)\left(\left[f_{1}+e_{1}\left(\frac{i_{t}}{k_{t}}\right)^{\eta_{1}-1}+e_{3}\left(\frac{q_{t} v_{t}}{n_{t}}\right)^{\eta_{3}}\left(\frac{i_{t}}{k_{t}}\right)^{\eta_{3}-1}\right]+\frac{p_{t}^{I}}{\frac{f_{t}}{k_{t}}}\right)\right] } \\
& +\left[\left(1-\psi_{t}\right)+\frac{q_{t} v_{t}}{n_{t}}\right]\left[\left(1-\tau_{t}\right)\left[f_{2}+e_{2}\left(\frac{q_{t} v_{t}}{n_{t}}\right)^{\eta_{2}-1}+e_{3}\left(\frac{i_{t}}{k_{t}}\right)^{\eta_{3}}\left(\frac{q_{t} v_{t}}{n_{t}}\right)^{\eta_{3}-1}\right]\right]+\xi_{t}
\end{aligned}
$$

The results are reported in Table C-2. They follow the same logic of constraining parameters as in Table 2 . 
There are two main conclusions from the table:

a. The point estimates are very similar to those of Table 2 .

b. The estimates are not precise: standard errors are large and the J statistics indicate rejection.

The first conclusion is due to the fact that essentially this is the same model, just reformulated, estimated on the same data set. The second conclusion is probably due to the fact that less restrictions are imposed on the data and less data are used (e.g., productivity and wage data are not used) relative to the three equation specification estimated in Table 2 (and in all other estimation tables).

\subsection{Robustness Checks}

We report variations on the basic specification to check for robustness. The variations pertain to the instrument set (the instruments used and their lags) and to alternative formulations of certain variables. These are reported in Tables C-3 and C-4. All variations are outlined in the notes to the tables.

The point estimates, and thus the implied cost function, are very similar across specifications. The major difference across columns pertains to the standard errors. Note that Table C-4 looks at alternative formulations of certain variables, using the instrument set of Table 2. Column 1 uses the sample averages for the depreciation rate $\delta$ and for the separation rate $\psi$. Columns 2 to 5 examine variations in $\beta$. Column 2 uses a discount factor based on the rate of growth of nondurable consumption, column 3 uses a discount factor based on the SP500 rate of change, column 4 uses a fixed discount factor $\beta=0.98$, and column 5 uses an alternative method of computing 
the basic specification (see Appendix B for exact formulations). Columns 6 and 7 use alternative formulations of $\frac{q v}{n}$ and $\psi$ as explained in Appendix B. The estimates are robust to the use of these alternative formulations. 


\section{Appendix D: The Interaction between Investment and Hiring}

In order to understand the significance of the $e_{3}$-estimates, it is useful to see how hiring depends on the value of investment and how investment depends on the value of hiring. First, consider the former case (hiring). The FONC may be re-written as follows:

$$
\begin{array}{ll}
F 1: & \left(\widetilde{g}_{i_{t}}\left(\frac{i_{t}}{k_{t}}, \frac{q_{t} v_{t}}{n_{t}}\right)+p_{t}^{I}\right)=Q_{t}^{k} \\
F 2 & : \frac{1}{q_{t}} \widetilde{g}_{v_{t}}\left(\frac{i_{t}}{k_{t}}, \frac{q_{t} v_{t}}{n_{t}}\right)=Q_{t}^{N} .
\end{array}
$$

Differentiate both equations with respect to $Q^{K}$ yields:

$$
\begin{aligned}
\frac{\partial \widetilde{g}_{i_{t}}}{\partial \frac{i_{t}}{k_{t}}} \frac{\partial \frac{i_{t}}{k_{t}}}{\partial Q^{k}}+\frac{\partial \widetilde{g}_{i_{t}}}{\partial \frac{q_{t} v_{t}}{n_{t}}} \frac{\partial \frac{q_{t} v_{t}}{n_{t}}}{\partial Q^{k}}=1 \\
\frac{1}{q_{t}}\left[\frac{\partial \widetilde{g}_{v_{t}}}{\partial \frac{i_{t}}{k_{t}}} \frac{\partial \frac{i_{t}}{k_{t}}}{\partial Q^{k}}+\frac{\partial \widetilde{g}_{v_{t}}}{\partial \frac{q_{t} v_{t}}{n_{t}}} \frac{\partial \frac{q_{t} v_{t}}{n_{t}}}{\partial Q^{k}}\right]=0
\end{aligned}
$$

where we use the following notation:

$$
g_{i i}=\frac{\partial \widetilde{g}_{i_{t}}}{\partial \frac{i_{t}}{k_{t}}} g_{i v}=\frac{\partial \widetilde{g}_{i_{t}}}{\partial \frac{q_{t} v_{t}}{n_{t}}} g_{v i}=\frac{1}{q} \frac{\partial \widetilde{g}_{v_{t}}}{\partial \frac{i_{t}}{k_{t}}} g_{v v}=\frac{1}{q} \frac{\partial \widetilde{g}_{v_{t}}}{\partial \frac{q_{t} v_{t}}{n_{t}}}
$$

Then:

$$
\begin{aligned}
g_{i i} \frac{\partial \frac{i_{t}}{k_{t}}}{\partial Q^{k}}+g_{i v} \frac{\partial \frac{q_{t} v_{t}}{n_{t}}}{\partial Q^{k}} & =1 \\
g_{v i} \frac{\partial \frac{i_{t}}{k_{t}}}{\partial Q^{k}}+g_{v v} \frac{\partial \frac{q_{t} v_{t}}{n_{t}}}{\partial Q^{k}} & =0
\end{aligned}
$$

Solving for the marginal effect of $Q^{K}$ on investment and on hiring yields:

$$
\begin{aligned}
\frac{\partial \frac{i_{t}}{k_{t}}}{\partial Q^{k}} & =\frac{g_{v v}}{g_{i i} g_{v v}-g_{i v} g_{v i}}>0 \\
\frac{\partial \frac{q_{t} v_{t}}{n_{t}}}{\partial Q^{k}} & =-\frac{g_{v i}}{g_{i i} g_{v v}-g_{i v} g_{v i}} .
\end{aligned}
$$


With a convex adjustment costs function $g$, the denominator is positive. Evidently investment rates rise with $Q^{K}$; its effect on hiring $\left(\frac{\partial \frac{q_{t} v_{t}}{n_{t}}}{\partial Q^{k}}\right)$ depends on the sign of $g_{v i}$. A negative point estimate of $e_{3}$ implies a negative value for $g_{v i}$ and, therefore, a positive sign for $\partial \frac{q_{t} v_{t}}{n_{t}} / \partial Q^{k}$. Hence, when $Q^{K}$ rises both $\frac{i}{k}$ and $\frac{q v}{n}$ rise.

Using a similar argument we can show that $\frac{i}{k}$ and $\frac{q v}{n}$ rise with an increase in $Q^{N}$. 


\section{Tables}

Table 1

Descriptive Sample Statistics

\begin{tabular}{lcc}
\hline \hline Variable & Mean & Standard Deviation \\
\hline$\frac{i}{k}$ & 0.023 & 0.004 \\
\hline$\frac{f}{k}$ & 0.17 & 0.01 \\
\hline$\tau$ & 0.39 & 0.06 \\
\hline$\delta$ & 0.016 & 0.003 \\
\hline \hline$\frac{w n}{f}$ & 0.66 & 0.01 \\
\hline$\frac{q v}{n}$ & 0.089 & 0.009 \\
\hline$\psi$ & 0.086 & 0.009 \\
\hline \hline$\frac{s}{f}$ & 6.0 & 2.1 \\
\hline$\beta$ & 0.989 & 0.006 \\
\hline
\end{tabular}

Note: The sample size contains 108 quarterly observations from 1976:1 to 2002:4. For data definitions see Appendix B. 
Table 2

GMM Estimates of (F1), (F2) and (2.20)

\begin{tabular}{|c|c|c|c|c|}
\hline & 1 & 2 & 3 & 4 \\
\hline constrained powers & all free & $\eta_{2}, \eta_{3}$ & $\eta_{1}, \eta_{3}$ & $\eta_{1}, \eta_{2}$ \\
\hline \multirow[t]{2}{*}{$\eta_{1}$} & 2.80 & 2.80 & 2.80 & 2.80 \\
\hline & $(0.04)$ & $(0.03)$ & - & - \\
\hline \multirow[t]{2}{*}{$\eta_{2}$} & 3.40 & 3.40 & 3.41 & 3.40 \\
\hline & $(0.15)$ & - & $(0.10)$ & - \\
\hline \multirow[t]{2}{*}{$\eta_{3}$} & 2.00 & 2.00 & 2.00 & 2.00 \\
\hline & $(0.002)$ & - & - & $(0.001)$ \\
\hline \multirow[t]{2}{*}{$e_{1}$} & 16,123 & 16,144 & 15,929 & 15,851 \\
\hline & $(4,784)$ & $(3,919)$ & (772) & $(1,460)$ \\
\hline \multirow[t]{2}{*}{$e_{2}$} & 2,772 & 2,851 & 2,936 & 2,849 \\
\hline & $(1,364)$ & (306) & $(992)$ & $(312)$ \\
\hline \multirow[t]{2}{*}{$e_{3}$} & $-102,291$ & $-102,229$ & $-102,475$ & $-101,529$ \\
\hline & $(25,266)$ & $(6,873)$ & $(6,975)$ & $(18,553)$ \\
\hline \multirow[t]{2}{*}{$f_{1}$} & 1.98 & 2.08 & 2.12 & 1.99 \\
\hline & (15.89) & $(6.87)$ & $(0.99)$ & ( 6.21$)$ \\
\hline \multirow[t]{2}{*}{$f_{2}$} & -2.02 & -2.01 & -1.91 & -2.00 \\
\hline & $(2.78)$ & $(0.72)$ & $(2.08)$ & $(0.82)$ \\
\hline \multirow[t]{2}{*}{$\alpha$} & 0.69 & 0.69 & 0.69 & 0.69 \\
\hline & $(0.10)$ & $(0.06)$ & $(0.09)$ & $(0.08)$ \\
\hline J-Statistic & 60.1 & 58.3 & 56.9 & 58.0 \\
\hline p-Value & 0.11 & 0.20 & 0.23 & 0.21 \\
\hline
\end{tabular}




\begin{tabular}{|c|c|c|c|}
\hline & 5 & 6 & 7 \\
\hline constrained scale & \multicolumn{3}{|c|}{$f_{1}=2 ;, f_{2}=-2$} \\
\hline constrained powers & $\eta_{2}, \eta_{3}$ & $\eta_{1}, \eta_{3}$ & $\eta_{1}, \eta_{2}$ \\
\hline \multirow[t]{2}{*}{$\eta_{1}$} & 2.80 & 2.80 & 2.80 \\
\hline & $(0.003)$ & - & - \\
\hline \multirow[t]{2}{*}{$\eta_{2}$} & 3.40 & 3.40 & 3.40 \\
\hline & - & $(0.02)$ & - \\
\hline \multirow[t]{2}{*}{$\eta_{3}$} & 2.00 & 2.00 & 2.00 \\
\hline & - & - & $(0.0001)$ \\
\hline \multirow[t]{2}{*}{$e_{1}$} & 16,197 & 16,024 & 16,049 \\
\hline & $(847)$ & $(742)$ & $(636)$ \\
\hline \multirow[t]{2}{*}{$e_{2}$} & 2,830 & 2,976 & 2,828 \\
\hline & $(229)$ & $(508)$ & $(247)$ \\
\hline \multirow[t]{2}{*}{$e_{3}$} & $-103,334$ & $-103,352$ & $-103,859$ \\
\hline & $(5,382)$ & $(6,303)$ & $(5,609)$ \\
\hline \multirow[t]{2}{*}{$\alpha$} & 0.68 & 0.68 & 0.69 \\
\hline & $(0.02)$ & $(0.03)$ & $(0.02)$ \\
\hline J-Statistic & 62.2 & 58.2 & 63.1 \\
\hline $\mathrm{p}$-value & 0.16 & 0.26 & 0.14 \\
\hline
\end{tabular}

\section{Notes:}

1. The table reports the point estimates of the parameters and standard errors in parentheses (except where constrained).

2. Instruments used are a constant and 6 lags of $\left\{\frac{i_{t-j}}{k_{t-j}}, \frac{q_{t-j} v_{t-j}}{n_{t-j}}, \frac{s_{t-j}}{f_{t-j}}\right\}$.

3. The top rows delineate which parameters are constrained. 
Table 3

GMM Estimates of $(F 1),(F 2)$ and (2.20)

Alternative Specifications

\begin{tabular}{|c|c|c|c|}
\hline & 1 & 2 & 3 \\
\hline & quadratic & $\eta_{1}=\eta_{2}=3$ & no hiring equation \\
\hline constraints & $f_{1}=f_{2}=e_{2}=e_{3}=0$ & $e_{3}=0 ; f 1=2 ; f 2=-2$ & $\eta_{1}, \eta_{3} ; f 1=2 ; f 2=-2$ \\
\hline \multirow[t]{2}{*}{$\eta_{1}$} & 2 & 3 & 2.80 \\
\hline & - & - & - \\
\hline \multirow[t]{2}{*}{$\eta_{2}$} & - & 3 & 3.40 \\
\hline & - & - & $(0.06)$ \\
\hline \multirow[t]{2}{*}{$\eta_{3}$} & - & - & 2 \\
\hline & - & - & - \\
\hline \multirow[t]{2}{*}{$e_{1}$} & 152 & 7,497 & 15,786 \\
\hline & $(7.8)$ & $(213)$ & $(1,537)$ \\
\hline \multirow[t]{2}{*}{$e_{2}$} & 0 & 116 & 2,774 \\
\hline & - & (12) & (1251) \\
\hline \multirow[t]{2}{*}{$e_{3}$} & 0 & 0 & $-100,914$ \\
\hline & - & - & $(14,623)$ \\
\hline \multirow[t]{2}{*}{$\alpha$} & 0.81 & 0.59 & 0.71 \\
\hline & $(0.04)$ & $(0.01)$ & $(0.16)$ \\
\hline J-Statistic & 66.0 & 74.3 & 46.4 \\
\hline p-Value & 0.002 & 0.04 & 0.06 \\
\hline
\end{tabular}

\section{Notes:}

1. The table reports the point estimates of the parameters and standard errors in paren- 
theses.

2. Instruments used are a constant and 6 lags of $\left\{\frac{i_{t-j}}{k_{t-j}}, \frac{q_{t-j} v_{t-j}}{n_{t-j}}, \frac{s_{t-j}}{f_{t-j}}\right\}$.

3. The third row delineates which parameters are constrained. 
Table 4

Estimated Total and Marginal Adjustment Costs

\begin{tabular}{cccc||cc} 
& \multicolumn{2}{c||}{ Table 2, column 7 } & Table 3, column 1 \\
\hline \hline & $\begin{array}{c}\text { value } \\
\text { at mean }\end{array}$ & $\begin{array}{c}\text { estimates } \\
\text { std. }\end{array}$ & $\begin{array}{c}\text { value } \\
\text { at mean }\end{array}$ & $\begin{array}{c}\text { estimates } \\
\text { std. }\end{array}$ \\
\hline \hline total & $\frac{g}{f}$ & 0.023 & 0.018 & 0.042 & 0.002 \\
marginal hiring & $\frac{g_{v}}{f / n}$ & 1.48 & 0.57 & & \\
& & & & & \\
marginal investment & $\frac{g_{i}}{f / k}$ & 1.31 & 0.54 & 3.55 & 0.18
\end{tabular}

\section{Notes:}

1. The 'value at mean' statistics refer to the relevant expression evaluated at the sample mean of $\frac{i_{t}}{k_{t}}$ and $\frac{q_{t} v_{t}}{n_{t}}$

2. Estimates standard deviation statistics refer to the root of the variance of the relevant cost expression, computed using the variance-co-variance matrix of the estimated parameters. The variables are evaluated at their sample mean.

3. All moments use the point estimates of the parameters estimated in the specification given in the first row. 
Table 5

Estimates of Marginal Installation Costs $(M C)$ for Capital

A. Summary of Selected Studies for the U.S. Economy

$M C=\gamma \frac{I}{K}$ (unless noted otherwise)

\begin{tabular}{|c|c|c|c|c|c|}
\hline & Study & Sample & $\gamma$ & Mean $\frac{I}{K}$ & Mean $M C$ \\
\hline 1 & Summers 1981 & BEA, 1932-1978 & 32.26 & 0.13 & 4.29 \\
\hline 2 & Hayashi 1982 & Corp. Sector, 1953-1976 & 23.64 & 0.14 & 3.31 \\
\hline 3 & Shapiro 1986 & Manufacturing, 1955-1980 & 2.35 & 0.08 & 0.19 \\
\hline 4 & Hubbard et al. 1995 & Compustat, 1976-1987 & 0.91 & 0.23 & 0.21 \\
\hline $5 \mathrm{a}$ & Cummins et al. 1994 & Compustat 1953-1988 & $17.54-52.6$ & 0.18 & $3.19-9.47$ \\
\hline $5 b$ & & Tax adjusted & $3.34-5.06$ & 0.18 & $0.60-0.91$ \\
\hline $6 a$ & Gilchrist & Compustat, 1985-1989 & 30.30 & 0.17 & 5.15 \\
\hline $6 \mathrm{~b}$ & and Himmelberg 1995 & Fundamental Q & 4.13 & 0.17 & 0.70 \\
\hline $7 a$ & Gilchrist & Compustat, 1980-1993 & 0.79 & 0.23 & 0.18 \\
\hline $7 \mathrm{~b}$ & and Himmelberg 1998 & High vs. Low Dividend & $0.54-4.65$ & 0.23 & $0.12-1.07$ \\
\hline \multirow[t]{3}{*}{8} & Barnett, Sakellaris 1999 & Compustat, 1960-1987 & $\gamma_{2}=1.44$ & 0.20 & 0.27 \\
\hline & & & $\gamma_{3}=-.36$ & & \\
\hline & & & $\gamma_{4}=.023$ & & \\
\hline 9 & Cooper, Ejarque 2003 & simulated based on LRD & 0.15 & 0.17 & 0.025 \\
\hline 10 & Cooper, Haltiwanger 2005 & LRD panel, 1972-1988 & 0.195 & 0.12 & 0.023 \\
\hline
\end{tabular}

\section{Notes:}

1. Investment rates $\frac{i}{k}$ and marginal costs are expressed in annual terms.

2. All studies use annual data, except Shapiro (1986) who uses quarterly data. For the latter study, i.e. study (3), Shapiro (1986) uses the formulation $M C=g_{k k} \cdot i_{t} \cdot y_{t}$. We represent this xxiv 
marginal installation cost alternatively as $M C=\frac{g_{k k} \cdot y \cdot k}{4} \cdot \frac{i}{k} \equiv \gamma \cdot \frac{i}{k}$. With an estimate of $g_{k k}=0.0014$ and his data averages, we get $\gamma=9.38$ in quarterly data and $\gamma=2.35$ in annual data.

3. In study (8) $M C=\gamma_{2} \frac{I}{K}+\gamma_{3}\left(\frac{I}{K}\right)^{2}+\gamma_{4}\left(\frac{I}{K}\right)^{3}$.

4. The parameter estimates in Hubbard et al (1995) pertain to their full sample. Those of Gilchrist and Himmelberg (1995) relate to the full sample, and the estimation with Tobin's Q (6a) and a fundamental Q (6b), respectively. The estimates in Gilchrist and Himmelberg (1998) relate to the sales-based measure of Tobin's Q. Line 7a reports full-sample results, and line 7b reports the range of estimates for firms with a low vs. high dividend payout. The estimate of Cooper and Haltiwanger (2005) is based on the following procedure: “...searched over quadratic adjustment costs models to find the value of $\gamma$ to maximize the $R^{2}$ between the series created by the best fit model and that created by the quadratic model. A value of $\gamma=0.195$ solved this maximization problem and the $R^{2}$ measure was 0.859." (page 23)

5. The studies cited are:

\section{References}

[1] Barnett, S.A. and P. Sakellaris 1999. "A New Look at Firm Market Value, Investment, and Adjustment Costs," The Review of Economics and Statistics 81:250-260.

[2] Cooper, R. and J. Ejarque 2003. "Financial Frictions and Investment: A Requiem in Q," Review of Economic Dynamics 6:710-728.

[3] Cooper, R. and J. Haltiwanger 2005. "On the Nature of Capital Adjustment Costs," Working Paper available online at http://www.eco.utexas.edu/ cooper/

[4] Cummins, J. G., K. A. Hassett, and R. G. Hubbard 1994. "A Reconsideration of Investment Behavior Using Tax Reforms As Natural Experiments," Brookings Papers on Economic Activity 1994, 2, 1-74. 
[5] Gilchrist, S. and C.P. Himmelberg 1995. "Evidence on the Role of Cash Flow for Investment," Journal of Monetary Economics 36:541-572.

[6] ______ 1998. "Investment: Fundamentals and Finance," NBER Macroeconomic Annual $223-262$.

[7] Hayashi, F. 1982. "Tobin's marginal q and Average q: A Neoclassical Interpretation," Econometrica 50:213-224.

[8] Hubbard, R.G., A.K Kashyap, and T.M. Whited 1995. "Internal Finance and Firm Investment," Journal of Money, Credit and Banking 27:683-701.

[9] Shapiro, M.D. 1986. "The Dynamic Demand for Capital and Labor," The Quarterly Journal of Economics 101:513-542.

[10] Summers, L.H. 1981. "Taxation and Corporate Investment: A q-Theory Approach," Brookings Papers on Economic Activity 1:67-127. 


\section{B. Implications of the Estimates}

\section{Total and Marginal Costs}

\begin{tabular}{|c|c|c|c|c|c|}
\hline & $\gamma$ & \multicolumn{2}{|c|}{$\frac{T C}{F}=\frac{\frac{\gamma}{2}\left(\frac{I}{K}\right)^{2}}{\frac{F}{K}}$} & \multicolumn{2}{c|}{$\frac{M C}{\frac{F}{K}}=\frac{\gamma \frac{I}{K}}{\frac{F}{K}}=\gamma \frac{I}{F}$} \\
\hline & & $\frac{I}{K}=0.10$ & $\frac{I}{K}=0.20$ & $\frac{I}{F}=0.15$ & $\frac{I}{F}=0.20$ \\
\hline \hline high & 50 & $0.37,0.50$ & $0.77,1$ & 7.5 & 10 \\
\hline & 20 & $0.15,0.20$ & $0.31,0.40$ & 3 & 4 \\
\hline \hline moderate & 3 & $0.02,0.03$ & $0.05,0.06$ & 0.45 & 0.60 \\
\hline & 0.7 & $0.005,0.007$ & $0.01,0.014$ & 0.11 & 0.14 \\
\hline \hline low & 0.2 & $0.001,0.002$ & $0.003,0.004$ & 0.03 & 0.04 \\
\hline
\end{tabular}

\section{Notes:}

1. The two values in the $\frac{T C}{F}$ column are based on computations which use alternative values of $\frac{F}{K}$. These are computed using $\frac{F}{K}=\frac{\frac{I}{K}}{\frac{T}{F}}$ as follows:

$$
\begin{array}{cc|cc} 
& & \multicolumn{2}{|c}{I / F} \\
& & 0.15 & 0.20 \\
\hline \multirow{2}{*}{I / K} & 0.10 & 0.67 & 0.5 \\
& 0.20 & 1.3 & 1
\end{array}
$$

Hence for every $I / K$ value there are two alternative $\frac{F}{K}$ values, as two values of $\frac{I}{F}$ are used. 
Table 6

Hiring and Investment Co-Movement

\section{Correlations}

\begin{tabular}{|c|c|}
\hline$\rho\left(\frac{i_{t}}{k_{t}}, \frac{q_{t} v_{t}}{n_{t}}\right)$ & -0.63 \\
\hline$\rho\left(\frac{Q_{t}^{K}}{\frac{f_{t}}{k_{t}}}, \frac{\left.Q_{t}^{N}\right)}{\frac{f_{t}}{n_{t}}}\right.$ & -0.98 \\
\hline$\rho\left(\frac{Q_{t}^{K}}{\frac{f_{t}}{k_{t}}}, \frac{i_{t}}{k_{t}}\right)$ & 0.87 \\
\hline$\rho\left(\frac{Q_{t}^{K}}{\frac{f_{t}}{k_{t}}}, \frac{q_{t} v_{t}}{n_{t}}\right)$ & -0.92 \\
\hline$\rho\left(\frac{Q_{t}^{N}}{\frac{f_{t}}{n_{t}}}, \frac{q_{t} v_{t}}{n_{t}}\right)$ & 0.88 \\
\hline$\rho\left(\frac{Q_{t}^{N}}{\frac{f_{t}}{n_{t}}}, \frac{i_{t}}{k_{t}}\right)$ & -0.92 \\
\hline
\end{tabular}

\section{Notes:}

1. The estimated asset values are given by:

$$
\begin{aligned}
\frac{Q^{K}}{\frac{f_{t}}{k_{t}}} & =\left(1-\tau_{t}\right) \frac{\left(g_{i_{t}}+p_{t}^{I}\right)}{\frac{f_{t}}{k_{t}}} \\
\frac{Q_{t}^{N}}{\frac{f_{t}}{n_{t}}} & =\left(1-\tau_{t}\right) \frac{\frac{g_{v_{t}}}{\frac{f_{t}}{n_{t}}}}{n_{t}}
\end{aligned}
$$

2. Point estimates used are those of Table 2, column 7. 
Table 7

Actual vs. Predicted Asset Value $\frac{s}{f}$

\section{Goodness of Fit}

\section{A. Moments}

\begin{tabular}{|c|c|c|c|c|}
\hline & actual $\frac{s_{t}}{f_{t}}$ & $\begin{array}{l}\text { predicted }\left(\frac{s_{t}}{f_{t}}\right)^{t} \\
\text { full model }\end{array}$ & quadratic & no interaction \\
\hline mean & 6.15 & 5.97 & 5.80 & 6.79 \\
\hline median & 5.66 & 5.63 & 5.85 & 6.64 \\
\hline standard deviation & 2.16 & 1.82 & 0.22 & 0.60 \\
\hline auto-correlation & 0.97 & 0.92 & 0.89 & 0.97 \\
\hline skewness & 0.94 & 0.78 & -0.54 & 0.78 \\
\hline kurtosis & 3.10 & 2.92 & 2.78 & 3.13 \\
\hline
\end{tabular}

B. Correlations $\rho\left(\left(\frac{\widetilde{s_{t}}}{f_{t}}\right)^{t}, \frac{s_{t}}{f_{t}}\right)$

full model quadratic no interaction

\begin{tabular}{lll}
\hline \hline 0.89 & 0.14 & 0.71 \\
\hline
\end{tabular}

\section{Notes:}

1. Moments are based on the following specifications for predicted values:

$$
\left(\frac{\widetilde{s_{t}}}{f_{t}}\right)^{t}=\left[\left(1-\delta_{t}\right)+\frac{i_{t}}{k_{t}}\right]\left[\left(1-\tau_{t}\right) \frac{\left(g_{i_{t}}+p_{t}^{I}\right)}{\frac{f_{t}}{k_{t}}}\right]+\left[\left(1-\psi_{t}\right)+\frac{q_{t} v_{t}}{n_{t}}\right]\left[\left(1-\tau_{t}\right) \frac{\frac{g_{v_{t}}}{q_{t}}}{\frac{f_{t}}{n_{t}}}\right]
$$

2. The predicted values use the point estimates of the following:

a. Full model use the results of Table 2, column 7 .

b. Quadratic use the results of Table 3, column 1 .

c. No interaction use the results of Table 3, column 2 .

xxix 
Table 8

Decomposition of Predicted Market Values $\widetilde{\left(\frac{s_{t}}{f_{t}}\right)}{ }^{t}$

a. Decomposition of the Mean

\begin{tabular}{|l|l|}
\hline Share of $\left(\frac{s_{t}}{f_{t}}\right)^{1}$ & 0.67 \\
\hline Share of $\left(\frac{s_{t}}{f_{t}}\right)^{2}$ & 0.11 \\
\hline Share of $\left(\frac{s_{t}}{f_{t}}\right)^{3}$ & 0.22 \\
\hline
\end{tabular}

b. Simulated Share of Neoclassical Part $\left(\frac{s_{t}}{f_{t}}\right)^{1}$

\begin{tabular}{|l|l|l|}
\hline variables & $\beta$ & 0.989154 \\
\hline & $\tau$ & 0.394444 \\
\hline & $\frac{f_{t+1}}{f_{t}}$ & 1.009012 \\
\hline & $\delta$ & 0.015784 \\
\hline & $\frac{f}{k}$ & 0.165408 \\
\hline calibrated parameters & $\frac{s}{f}$ & 6.039669 \\
\hline & $\left\{p^{I}, \alpha\right\}^{A}$ & $1,0.68$ \\
\hline & $\left\{p^{I}, \alpha\right\}^{B}$ & $1.2,0.64$ \\
\hline resulting share & $\left\{p^{I}, \alpha\right\}^{C}$ & $0.8,0.72$ \\
\hline & $\frac{\left(\frac{s}{f}\right)^{1}}{\frac{s}{f}}$ & 0.63 \\
\hline & $\frac{\left(\frac{s}{f}\right)^{1 B}}{\frac{s}{f}}$ & 0.75 \\
\hline & $\frac{\left(\frac{s}{f}\right)^{1 C}}{\frac{s}{f}}$ & 0.50 \\
\hline
\end{tabular}




\section{c. Variance Decomposition}

\begin{tabular}{c|ccc} 
& $\left(\frac{s_{t}}{f_{t}}\right)^{1}$ & $\left(\frac{s_{t}}{f_{t}}\right)^{2}$ & $\left(\frac{s_{t}}{f_{t}}\right)^{3}$ \\
\hline$\left(\frac{s_{t}}{f_{t}}\right)^{1}$ & 0.059 & -0.45 & 0.20 \\
$\left(\frac{s_{t}}{f_{t}}\right)^{2}$ & -0.45 & 4.45 & -1.94 \\
$\left(\frac{s_{t}}{f_{t}}\right)^{3}$ & 0.20 & -1.94 & 0.87
\end{tabular}

\section{Notes:}

1. Moments are based on the following specifications for predicted values:

$$
\begin{aligned}
& \left(\frac{\widetilde{s_{t}}}{f_{t}}\right)^{t}=\left[\left(1-\delta_{t}\right)+\frac{i_{t}}{k_{t}}\right]\left[\left(1-\tau_{t}\right) \frac{\left(g_{i_{t}}+p_{t}^{I}\right)}{\frac{f_{t}}{k_{t}}}\right]+\left[\left(1-\psi_{t}\right)+\frac{q_{t} v_{t}}{n_{t}}\right]\left[\left(1-\tau_{t}\right) \frac{\frac{g_{v_{t}}}{q_{t}}}{\frac{f_{t}}{n_{t}}}\right] \\
& \left(\frac{s_{t}}{f_{t}}\right)^{1}=\left[\left(1-\delta_{t}\right)+\frac{i_{t}}{k_{t}}\right]\left[\left(1-\tau_{t}\right) \frac{p_{t}^{I}}{\frac{f_{t}}{k_{t}}}\right] \\
& \left(\frac{s_{t}}{f_{t}}\right)^{2}=\left[\left(1-\delta_{t}\right)+\frac{i_{t}}{k_{t}}\right]\left[\left(1-\tau_{t}\right) \frac{g_{i_{t}}}{\frac{f_{t}}{k_{t}}}\right] \\
& \left(\frac{s_{t}}{f_{t}}\right)^{3}=\left[\left(1-\psi_{t}\right)+\frac{q_{t} v_{t}}{n_{t}}\right]\left[\left(1-\tau_{t}\right) \frac{\frac{g_{v_{t}}}{q_{t}}}{\frac{f_{t}}{n_{t}}}\right]
\end{aligned}
$$

2. The predicted values use the point estimates of Table 2 , column 7 . 
Table C-1

Instruments Relevance Tests

\begin{tabular}{|c|c|c|c|c|c|c|c|c|}
\hline instrument set & lags & \multicolumn{3}{|c|}{ 1st stage F stat } & \multicolumn{3}{|c|}{ Adjusted Partial $\bar{R}_{p}^{2}$} \\
\hline & & $\frac{i}{k}$ & $\frac{q v}{n}$ & $\frac{s}{f}$ & $\frac{i}{k}$ & $\frac{q v}{n}$ & $\frac{s}{f}$ \\
\hline \hline$\frac{i_{t-j}}{k_{t-j}}$ & $1-8$ & 712.5 & 7.7 & 12.5 & 0.05 & 0.15 & 0.00 \\
\hline$\frac{q_{t-j} v_{t-j}}{n_{t-j}}$ & $1-8$ & 8.2 & 58.9 & 30.0 & -0.03 & 0.05 & 0.13 \\
\hline$\frac{s_{t-j}}{f_{t-j}}$ & $1-8$ & 19.6 & 23.4 & 189.6 & 0.02 & 0.10 & 0.32 \\
\hline$\frac{i_{t-j}}{k_{t-j}}, \frac{q_{t-j} v_{t-j}}{n_{t-j}}, \frac{s_{t-j}}{f_{t-j}}$ & $1-8$ & 263.2 & 22.9 & 65.7 & 0.92 & 0.62 & 0.71 \\
\hline$\frac{i_{t-j}}{k_{t-j}}, \frac{q_{t-j} v_{t-j}}{n_{t-j}}, \frac{s_{t-j}}{f_{t-j}}$ & $1-4$ & 501.9 & 55.9 & 144.4 & 0.92 & 0.64 & 0.71 \\
\hline$\frac{w_{t-j} n_{t-j}}{f_{t-j}}, \frac{f_{t-j}}{k_{t-j}}$ & & & & & & & \\
\hline$\beta_{t-j}, \tau_{t-j}$ & $1-8$ & 14.0 & 24.7 & 17.5 & 0.12 & 0.12 & 0.22 \\
\hline$\psi_{t-j}, \delta_{t-j}$ & $1-8$ & 1.6 & 12.3 & 8.0 & 0.08 & 0.20 & 0.16 \\
\hline$\beta_{t-j}, \tau_{t-j}, \psi_{t-j}, \delta_{t-j}, \frac{w_{t-j} n_{t-j}}{f_{t-j}}, \frac{f_{t-j}}{k_{t-j}}$ & $1-4$ & 36.1 & 36.1 & 21.6 & 0.75 & 0.48 & 0.42 \\
\hline$\beta_{t-j}, \tau_{t-j}, \psi_{t-j}, \delta_{t-j}, \frac{w_{t-j} n_{t-j}}{f_{t-j}}, \frac{f_{t-j}}{k_{t-j}}$ & $1-8$ & 25.4 & 17.3 & 11.7 & 0.80 & 0.51 & 0.43 \\
\hline
\end{tabular}

\section{Notes:}

1. F statistics are taken from regressions of each endogenous variable on the instrument set.

2. The adjusted $R_{p}^{2}$ statistic is constructed according to the methodology in Shea (1997). 
Table C-2

GMM Estimates of (10.6)

\begin{tabular}{|c|c|c|c|c|}
\hline & 1 & 2 & 3 & 4 \\
\hline constrained powers & all free & $\eta_{2}, \eta_{3}$ & $\eta_{1}, \eta_{3}$ & $\eta_{1}, \eta_{2}$ \\
\hline \multirow[t]{2}{*}{$\eta_{1}$} & 2.80 & 2.80 & 2.80 & 2.80 \\
\hline & $(0.53)$ & $(0.18)$ & - & - \\
\hline \multirow[t]{2}{*}{$\eta_{2}$} & 3.40 & 3.40 & 3.41 & 3.40 \\
\hline & $(17.7)$ & - & $(2.53)$ & - \\
\hline \multirow[t]{2}{*}{$\eta_{3}$} & 2.00 & 2.00 & 2.00 & 2.00 \\
\hline & $(0.21)$ & - & - & $(0.04)$ \\
\hline \multirow[t]{2}{*}{$e_{1}$} & 16,107 & 16,201 & 16,140 & 16,206 \\
\hline & $(41,545)$ & $(18,544)$ & $(9,740)$ & $(5,001)$ \\
\hline \multirow[t]{2}{*}{$e_{2}$} & 2,800 & 2,834 & 2,861 & 2,851 \\
\hline & $(36,933)$ & $(4,945)$ & $(19,425)$ & $(17,798)$ \\
\hline \multirow[t]{2}{*}{$e_{3}$} & $-102,141$ & $-103,379$ & $-103,094$ & $-103,166$ \\
\hline & $(314,005)$ & $(93,116)$ & $(83,317)$ & $(149,623)$ \\
\hline \multirow[t]{2}{*}{$f_{1}$} & 2.10 & 2.00 & -4.27 & 1.42 \\
\hline & $(790)$ & $(154)$ & $(158)$ & $(140)$ \\
\hline \multirow[t]{2}{*}{$f_{2}$} & -2.03 & -2.02 & 4.65 & -1.22 \\
\hline & $(527)$ & (127) & $(202)$ & $(160)$ \\
\hline J-Statistic & 31.4 & 32.3 & 31.9 & 31.9 \\
\hline p-Value & 0.001 & 0.002 & 0.002 & 0.002 \\
\hline
\end{tabular}

xxxiii 


\begin{tabular}{cccc}
\hline \hline & 5 & 6 & 7 \\
\hline constrained powers & $\eta_{2}, \eta_{3}$ & $\eta_{1}, \eta_{3}$ & $\eta_{1}, \eta_{2}$ \\
\hline constrained scale & \multicolumn{3}{c}{$f_{1}=2 ; f_{2}=-2$} \\
\hline$\eta_{1}$ & 2.80 & 2.80 & 2.80 \\
& $(0.01)$ & - & - \\
$\eta_{2}$ & 3.40 & 3.40 & 3.40 \\
& - & $(0.09)$ & - \\
$\eta_{3}$ & 2 & 2 & 2.00 \\
& - & - & $(0.001)$ \\
& & & \\
$e_{1}$ & 16,357 & 16,324 & 16,284 \\
& $(3,976)$ & $(3,112)$ & $(3,375)$ \\
$e_{2}$ & 2,887 & 2,916 & 2,874 \\
& $(1,391)$ & $(2,298)$ & $(1,830)$ \\
p-Value & $-104,384$ & $-104,436$ & $-104,013$ \\
$e_{3}$ & $(25,814)$ & $(27,965)$ & $(27,773)$ \\
& & & \\
\hline \multirow{2}{*}{ J-Statistic } & 32.6 & 32.6 & 32.7 \\
& 0.01 & 0.01 & 0.01 \\
\hline
\end{tabular}

\section{Notes:}

1. The table reports the point estimates of the parameters and standard errors in parentheses (except where constrained).

2. Instruments used are a constant and 6 lags of $\left\{\frac{i_{t-j}}{k_{t-j}}, \frac{q_{t-j} v_{t-j}}{n_{t-j}}, \frac{s_{t-j}}{f_{t-j}}\right\}$.

3. The top rows delineate which parameters are constrained. 
Table C-3

GMM Estimates of (F1), (F2) and (2.20)

Alternative Specifications - Variations on the Instrument Set

\begin{tabular}{|c|c|c|c|}
\hline & 1 & 2 & 3 \\
\hline instrument set & $\frac{i_{t-j}}{k_{t-j}}, \frac{q_{t-j} v_{t-j}}{n_{t-j}}, \frac{s_{t-j}}{f_{t-j}}$ & $\frac{i_{t-j}}{k_{t-j}}, \frac{q_{t-j} v_{t-j}}{n_{t-j}}, \frac{s_{t-j}}{f_{t-j}}$ & $\begin{array}{c}\beta_{t-j}, \tau_{t-j}, \psi_{t-j}, \\
\delta_{t-j}, \frac{w_{t-j} n_{t-j}}{f_{t-j}}, \frac{f_{t-j}}{k_{t-j}}\end{array}$ \\
\hline lags & 4 & 8 & 4 \\
\hline \multirow[t]{2}{*}{$\eta_{1}$} & 2.8 & 2.8 & 2.8 \\
\hline & - & - & - \\
\hline \multirow[t]{2}{*}{$\eta_{2}$} & 3.4 & 3.4 & 3.4 \\
\hline & - & - & - \\
\hline \multirow[t]{2}{*}{$\eta_{3}$} & 2.00 & 2.00 & 2.00 \\
\hline & $(0.0001)$ & $(0.0001)$ & $(0.0001)$ \\
\hline \multirow[t]{2}{*}{$e_{1}$} & 16,072 & 16,145 & 17,378 \\
\hline & $(756)$ & $(457)$ & (378) \\
\hline \multirow[t]{2}{*}{$e_{2}$} & 2,850 & 2,892 & 3,633 \\
\hline & (292) & (164) & (103) \\
\hline \multirow[t]{2}{*}{$e_{3}$} & $-103,896$ & $-104,015$ & $-121,723$ \\
\hline & $(7,401)$ & $(4,519)$ & $(2,852)$ \\
\hline \multirow[t]{2}{*}{$\alpha$} & 0.69 & 0.69 & 0.76 \\
\hline & $(0.03)$ & $(0.02)$ & $(0.02)$ \\
\hline J-Statistic & 52.6 & 74.4 & 76.6 \\
\hline p-Value & 0.02 & 0.34 & 0.28 \\
\hline
\end{tabular}

Notes:

XXXV 
1. The table reports the point estimates of the parameters and standard errors in parentheses.

2. Instruments used are reported in the second row.

3. Constrained parameters are reported in the table without standard errors. In addition $f_{1}=2, f_{2}=-2$. 
Table C-4

GMM Estimates of $(F 1),(F 2)$ and (2.20)

Alternative Specifications - Variations on Variables

\begin{tabular}{|c|c|c|c|c|c|c|c|}
\hline & 1 & 2 & 3 & 4 & 5 & 6 & 7 \\
\hline variable changed & $\delta, \psi$ & $\beta$ & $\beta$ & $\beta$ & $\beta$ & $\psi, \frac{q v}{n}$ & $\psi, \frac{q v}{n}$ \\
\hline \multirow[t]{2}{*}{$\eta_{1}$} & 2.8 & 2.8 & 2.8 & 2.8 & 2.8 & 2.8 & 2.8 \\
\hline & - & - & - & - & - & - & - \\
\hline \multirow[t]{2}{*}{$\eta_{2}$} & 3.4 & 3.4 & 3.4 & 3.4 & 3.4 & 3.4 & 3.4 \\
\hline & - & - & - & - & - & - & - \\
\hline \multirow[t]{2}{*}{$\eta_{3}$} & 2.00 & 2.00 & 2.00 & 2.00 & 2.00 & 2.00 & 2.00 \\
\hline & $(0.0001)$ & $(0.0001)$ & $(0.0001)$ & $(0.0001)$ & $(0.0001)$ & $(0.0001)$ & $(0.0001)$ \\
\hline \multirow[t]{2}{*}{$e_{1}$} & 16,070 & 16,091 & 16,065 & 16,020 & 16,072 & 15,914 & 15,930 \\
\hline & $(627)$ & (602) & (646) & (508) & $(677)$ & $(746)$ & $(538)$ \\
\hline \multirow[t]{2}{*}{$e_{2}$} & 2,842 & 2,845 & 2,847 & 2,847 & 2,846 & 2,877 & 2,181 \\
\hline & $(253)$ & $(212)$ & $(259)$ & (194) & $(257)$ & $(258)$ & $(129)$ \\
\hline \multirow[t]{2}{*}{$e_{3}$} & $-104,270$ & $-105,083$ & $-103,410$ & $-102,497$ & $-103,829$ & $-102,846$ & $-92,976$ \\
\hline & $(5,586)$ & $(4,958)$ & $(5,637)$ & $(4,572)$ & $(5,849)$ & $(7,189)$ & $(5,204)$ \\
\hline \multirow[t]{2}{*}{$f_{1}$} & 2 & 2 & 2 & 2 & 2 & 2 & 2 \\
\hline & - & - & - & - & - & - & - \\
\hline \multirow[t]{2}{*}{$f_{2}$} & -2 & -2 & -2 & -2 & -2 & -2 & -2 \\
\hline & - & - & - & - & - & - & - \\
\hline \multirow[t]{2}{*}{$\alpha$} & 0.69 & 0.68 & 0.69 & 0.69 & 0.69 & 0.71 & 0.67 \\
\hline & $(0.02)$ & $(0.02)$ & $(0.03)$ & $(0.02)$ & $(0.03)$ & $(0.03)$ & $(0.02)$ \\
\hline J-Statistic & 64.3 & 69.2 & 61.2 & 65.4 & 60.1 & 55.7 & 60.7 \\
\hline p-Value & 0.12 & 0.06 & 0.18 & 0.10 & 0.21 & 0.34 & 0.19 \\
\hline
\end{tabular}

xxxvii 


\section{Notes:}

1. The table reports the point estimates of the parameters and standard errors in parentheses.

2. Instruments used are a constant and 6 lags of $\left\{\frac{i_{t-j}}{k_{t-j}}, \frac{q_{t-j} v_{t-j}}{n_{t-j}}, \frac{s_{t-j}}{f_{t-j}}\right\}$.

3. Constrained parameters are reported in the table without standard errors.

4. Column 1 has $\delta=0.016$ and $\psi=0.086$. In column $2, \beta$ is based on non-durable consumption rate of growth, in column 3 on the SP500 rate of change, in column $4 \beta=0.98$ and in column $5, \beta$ is based on an alternative computation of the benchmark $\beta$. In columns 6 and 7 alternative definitions of $\psi$ and $\frac{q v}{n}$ are used. See the discussion in Appendix B for exact definitions. 


\section{Figures}
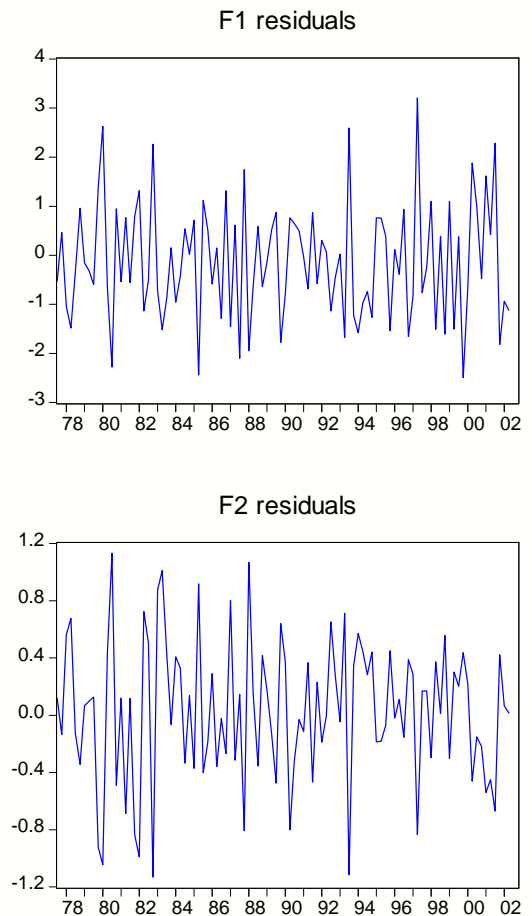

Figure 1: $F 1$ and $F 2$ residuals

\begin{tabular}{|c|c|c|}
\hline & $F 1$ & $F 2$ \\
\hline AR & -0.25 & -0.12 \\
\hline Ljung-Box Q test 1st lag- p value & 0.01 & 0.23 \\
\hline Ljung-Box Q test 2nd lag-p value & 0.03 & 0.13 \\
\hline Ljung-Box Q test 3rd lag- p value & 0.06 & 0.24 \\
\hline Ljung-Box Q test 4th lag- p value & 0.08 & 0.22 \\
\hline Breusch-Godfrey LM test - p value & 0.07 & 0.21 \\
\hline
\end{tabular}

xxxix 


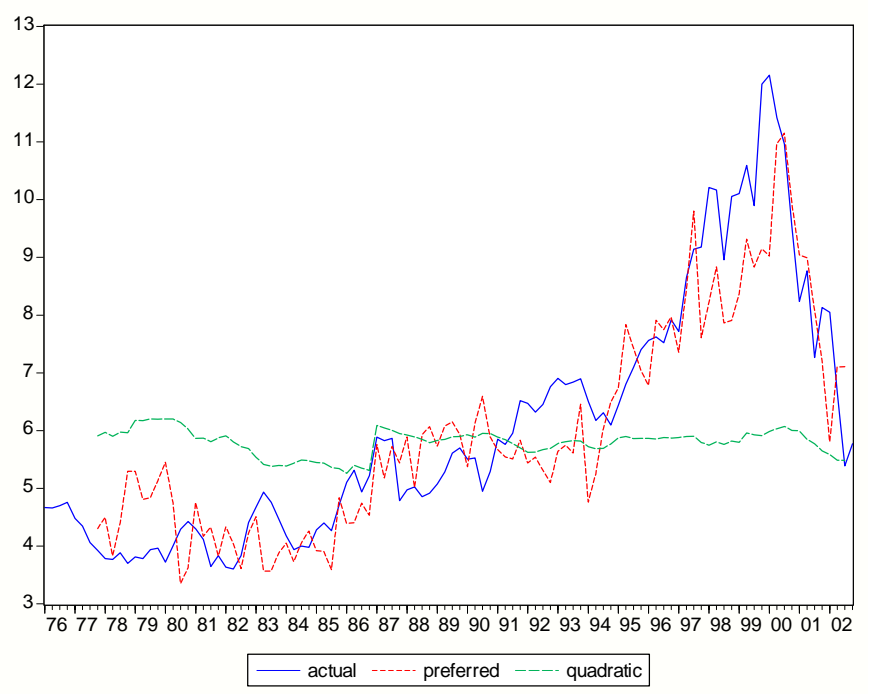

Figure 2a: Actual and predicted (preferred and quadratic) $\frac{s}{f}$

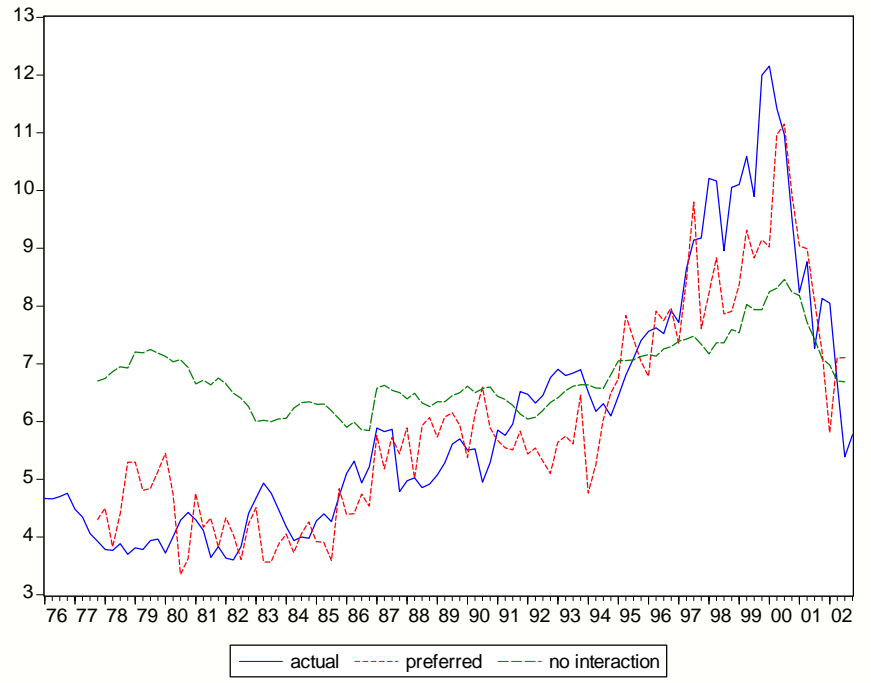

Figure 2b: Actual and predicted (preferred and no interaction) $\frac{s}{f}$ 


\section{CENTRE FOR ECONOMIC PERFORMANCE Recent Discussion Papers}

689 Pierre-Philippe Combes

Giles Duranton

Henry G. Overman

688 Stephen Redding

Daniel M. Sturm

687 Vicente Cuñat

Maria Guadalupe

686 Maria Guadalupe

685 Jo Blanden

Stephen Machin

John Van Reenen

684 Giovanna Vallanti

683 Gilles Duranton Michael Storper

682 Carlo Rosa

Giovanni Verga

681 Nicholas Oulton

Sylaja Srinivasan

680 Stephen Machin

Olivier Marie

679 Alan Manning

Barbara Petrongolo

678 Andrew Clark

Fabien Postel-Vinay

677 Eran Yashiv
Agglomeration and the Adjustment of the Spatial Economy

The Costs of Remoteness: Evidence from German Division and Reunification

How Does Product Market Competition Shape Incentive Contracts?

Product Market Competition, Returns to Skill and Wage Inequality

New Survey Evidence on Recent Changes in UK Union Recognition

Capital Mobility and Unemployment Dynamics:

Evidence from a Panel of OECD Countries

Rising Trade Costs? Agglomeration and Trade with Endogenous Transaction Costs

Is ECB Communication Effective?

Productivity Growth and the Role of ICT in the

United Kingdom: An Industry View, 1970-2000

Crime and Police Resources: the Street Crime Initiative

The Part-Time Pay Penalty

Job Security and Job Protection

Evaluating the Performance of the Search and Matching Model 
676 Alex Bryson

Rafael Gomez

Tobias Kretschmer

675 Nick Bloom

Mark Schankerman

John Van Reenen

674 Lorraine Dearden

Howard Reed

John Van Reenen

673 Giulia Faggio

Stephen Nickell

672 Chiara Criscuolo

Ralf Martin

671 Roberto Torrini

670 Silvia Ardagna

Francesco Caselli

Timothy Lane

669 Alejandro Cuñat

Marco Maffezzoli

668 Francesco Caselli

Silvana Tenreyro

667 Francesco Caselli

666 Gianluca Benigno

Pierpaolo Benigno

665 Olmo Silva
Catching a Wave: the Adoption of Voice and High Commitment Workplace Practices in Britain: 19841998

Identifying Technology Spillovers and Product Market Rivalry

The Impact of Training on Productivity and Wages: Evidence from British Panel Data

Inactivity Among Prime Age Men in the UK

Multinationals and US Productivity Leadership:

Evidence from Great Britain

Profit Share and Returns on Capital Stock in Italy: the Role of Privatisations Behind the Rise of the 1990s

Fiscal Discipline and the Cost of Public Debt Service: Some Estimates for OECD Countries

Can Comparative Advantage Explain the Growth of US Trade?

Is Poland the Next Spain?

Accounting for Cross-Country Income Differences

Designing Target Rules for International Monetary

Policy Cooperation

Entrepreneurship: Can the Jack-of-All-Trades

Attitude be Acquired?

\section{The Centre for Economic Performance Publications Unit Tel 02079557673 Fax $02079557595 \quad$ Email info@cep.lse.ac.uk Web site http://cep.Ise.ac.uk}

